\title{
Article \\ An Effective Simulation Scheme for Predicting the Aerodynamic Heat of a Scramjet-Propelled Vehicle
}

\author{
Lu Yang ${ }^{1,2}$ and Guangming Zhang ${ }^{1, *(1)}$ \\ 1 Department of Power Engineering and Engineering Thermophysics, College of Mechanical and \\ Power Engineering, Nanjing Tech University, Nanjing 210000, China; shaney19850430@163.com \\ 2 Anhui Public Security Education Research Institute (Anhui Public Security College Preparatory Office), \\ Hefei 230000, China \\ * Correspondence: zgm@njtech.edu.cn
}

Citation: Yang, L.; Zhang, G. An Effective Simulation Scheme for Predicting the Aerodynamic Heat of a Scramjet-Propelled Vehicle. Appl. Sci. 2021, 11, 9344. https://doi.org/ 10.3390/app11199344

Academic Editor: Adrian Irimescu

Received: 31 August 2021

Accepted: 5 October 2021

Published: 8 October 2021

Publisher's Note: MDPI stays neutral with regard to jurisdictional claims in published maps and institutional affiliations.

Copyright: (c) 2021 by the authors. Licensee MDPI, Basel, Switzerland. This article is an open access article distributed under the terms and conditions of the Creative Commons Attribution (CC BY) license (https:/ / creativecommons.org/licenses/by/ $4.0 /)$.

\begin{abstract}
Currently, aerothermal research into scramjet-propelled vehicles characterized by a wedgeshaped section is relatively sparse. Based on the Mach number, grid strategy, and numerical method, an effective simulation scheme for predicting the aerodynamic heat of a scramjet-propelled vehicle during flight is proposed in this paper. At different Mach numbers, the appropriate grid strategy and numerical method were determined by validation tests. Two-dimensional external flow field models based on wedge sections were established and, unlike in blunt bodies, the tests showed that at the high supersonic stage, the ideal cell Reynolds number should be no larger than 16 . At the hypersonic stage, the ideal cell Reynolds number and aspect ratio of wall cells near the shock should be no larger than 40, and the AUSM+ flux type performs better than Roe's FDS flux type at the above stages. The aerothermal prediction indicates that during a flight time of about $34 \mathrm{~s}$, the temperature change reaches about $1913.35^{\circ} \mathrm{C}$, and the maximum average temperature change rate reaches $115^{\circ} \mathrm{C} / \mathrm{s}$.
\end{abstract}

Keywords: aerodynamic heat prediction; scramjet propelled vehicle; simulation scheme

\section{Introduction}

Aerodynamic heat prediction plays an important role in the design and optimization of hypersonic vehicles [1,2]. In general, there are three technical approaches to aerodynamic heat prediction: the engineering estimation [3], the wind tunnel experiment [4], and computational fluid dynamics (CFD) [5,6]. With the development of computer technology, CFD has made great progress; its results offer higher accuracy than engineering estimation, and, unlike the wind tunnel experiment, its simulation ability can cover the entire flight trajectory. The CFD technology has become an indispensable means in the study of aerothermal predictions. Its results are influenced by many factors, such as Mach number, gird strategy, and numerical methods, which include turbulence models, upwind scheme, limiter, and so on. Domestic and foreign scholars have carried out research into these factors. The aerodynamic characteristics of different Mach numbers are different, and the corresponding grid strategy and numerical method are also different [7]. In terms of grid strategy, the height of the first layer of wall cells has a great influence on the numerical calculation results, and the mesh needs to be adjusted several times according to the CFD results, which is a time-consuming part of the CFD process. Ref. [8] discusses the effect of the grid on aerothermal prediction by taking an external flow field simulation model based on a blunt body as an example. The results show that the deviation of the results could reach more than $20 \%$ when the Reynolds number of the wall grid is doubled while other conditions are unchanged. Ref. [9] considers the effect of cell Reynolds numbers on aerothermal prediction by applying a cylinder as an example. The results show that it is necessary to keep the cell Reynolds number less than 10 in the aerothermal calculation, and Refs. [10,11] presents similar research cases. Ref. [12] shows that the property of shock stability influences the accuracy of heating prediction. Ref. [13] reveals that the aspect ratio 
of wall cells near the shock is a major factor and Ref. [14] suggests that the aspect ratio of wall cells near the shock should be larger than six for predicting hypersonic heating, taking a blunt body and a blunt cone as examples. The experimental data of X33, which is a reusable reentry hypersonic vehicle, are used to validate the above conclusions. In terms of the numerical method, turbulence is a difficult problem in flows and the current simulation equations for turbulence include Reynolds Averaged Navier-Stokes (RANS), Large Eddy, Separated Eddy, and Direct Numerical Simulation (DNS), etc. Considering the limitations of robustness and computational efficiency, RANS is still the main turbulence simulation method adopted at present [15]. When there are discontinuities in flows, the artificial viscosity, which can affect the calculation accuracy, is usually added to the central scheme to suppress oscillations. Therefore, varieties of upwind schemes have gradually become the mainstream approach to numerical calculation. In addition, the limiter is applied to limit the difference gradient to avoid oscillations. Ref. [16] discusses the calculation accuracy of AUSM+, Roe's FDS, and FVS by taking the flow around a cylinder and a blunt as examples. The results show that the calculation accuracy of these three upwind schemes is better than that of the central difference scheme, and the numerical results of AUSM+ and Roe's FDS are closer to the experimental data. Ref. [17] adopts Minmod, van leer, and osher-c limiters to simulate the external flow field of a blunt. The results indicate that the maximum heat flow value and heat distribution characteristics obtained by the Minmod limiter are better than the other two limiters.

In current research, the reusable reentry vehicle is the main research object of aerothermal prediction. The external flow field model for simulation is primarily based on blunt bodies, and the initial conditions of freestream are usually selected from a certain stage in the flight path, such as the hypersonic stage. However for the scramjet-propelled vehicle with a wedge section as its characteristic component, research on the aerodynamics heat prediction in the flight path is relatively sparse. In this study, a 2D external flow field model was built based on a wedge section, and an aerothermal prediction was performed for its flight path is performed. This approach can further enrich and improve aerothermal research into hypersonic vehicles.

This manuscript is organized as follows. In the second section, we briefly overview the flight path of a scramjet-propelled vehicle and the numerical procedures applied in the CFD. Next, according to the Mach number, the flight trajectory of the scramjet-propelled vehicle is divided into different stages, and the determination of the appropriate grid strategy and numerical method through validation tests is presented in the third section. Based on the simulation parameters confirmed in these sections, an effective simulation scheme for the scramjet-propelled vehicle is then proposed, and the prediction of the aerodynamic heat during the flight is discussed in in the fourth section. The last section presents our conclusions.

\section{Flight Path of Scramjet-Propelled Vehicle and Numerical Procedures}

Rocket-based combined cycle (RBCC) is the ideal power system for future scramjetpropelled vehicles and single-stage re-use vehicles. To minimize wave resistance during flight, RBCC vehicles tend to have a pointed head with a slender fuselage, and the typical part of RBCC vehicles is a wedge-shaped section. The X51A vehicle and its flight path are as shown in Figure 1a,b [18]. The flight path consists of a climbing phase, cruising phase, and attack phase, and the climbing phase also includes an ejection phase, a sub-combustion stamping phase, and a super-combustion stamping phase. During the climbing phase, the flight speed of the vehicle rapidly increases, and it is a phase of complex temperature changes. In the cruising phase, the vehicle keeps a constant altitude and speed and the flight distance accounts for about $90 \%$ of the total range; it could be viewed as a steady-state phase. These two phases are the main phases of the flight path, and the simulation scheme for aerodynamic heat prediction is proposed covering these two phases in this paper. After arriving at the target airspace, the vehicle enters the attack phase, in which it shifts down and attacks the target accurately. 


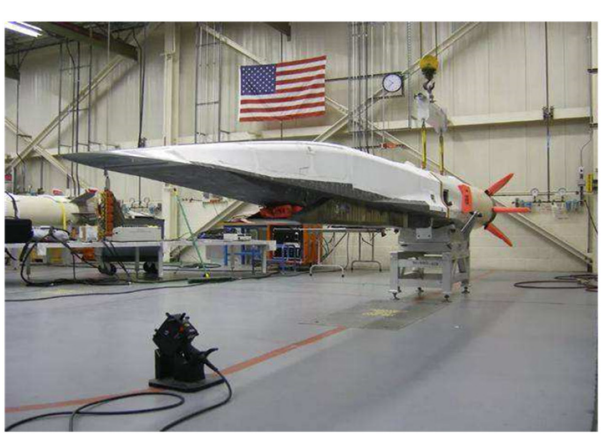

(a)

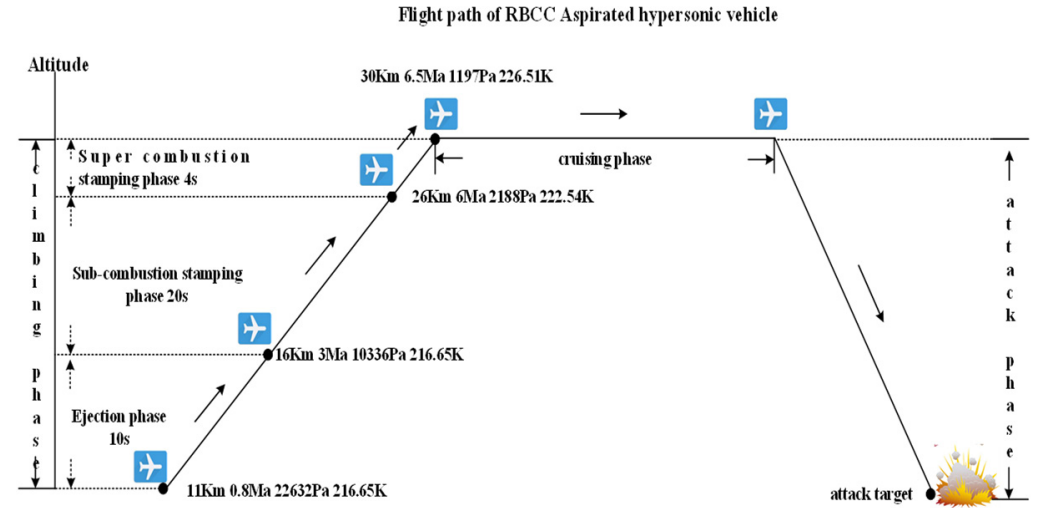

(b)

Figure 1. (a) X51A; (b) The flight path of an RBCC scramjet-propelled vehicle. The initial conditions of flow at different phases are as follows: Climbing phase: (1) ejection phase, duration time is about $10 \mathrm{~s}$. Flight altitude is about $11 \mathrm{~km}$, Mach number is 0.8 , pressure is $22,700 \mathrm{~Pa}$, temperature is $216.77 \mathrm{~K}$, air density is $0.3648 \mathrm{~kg} / \mathrm{m}^{3}$ and dynamic viscosity is $1.422 \times 10^{-5} \mathrm{~Pa} \cdot \mathrm{s}$. (2) sub-combustion stamping phase, duration time is about $20 \mathrm{~s}$. Flight altitude is about $16 \mathrm{~km}$, Mach number is 3, pressure is $10,350 \mathrm{~Pa}$, temperature is $216.65 \mathrm{~K}$, air density is $0.1663 \mathrm{~kg} / \mathrm{m}^{3}$ and dynamic viscosity is $1.422 \times 10^{-5} \mathrm{~Pa} \cdot \mathrm{s}$. (3) super-combustion stamping phase, duration time is about $4 \mathrm{~s}$, flight altitude is about $26 \mathrm{~km}$, Mach number is 6, pressure is $2188 \mathrm{~Pa}$, temperature is $222.54 \mathrm{~K}$, air density is $0.0339 \mathrm{~kg} / \mathrm{m}^{3}$ and dynamic viscosity is $1.454 \times 10^{-5} \mathrm{~Pa} \cdot \mathrm{s}$. Cruising phase: the flight altitude is about $30 \mathrm{~km}$, Mach number is 6.5, pressure is $1197 \mathrm{~Pa}$, temperature is $226.51 \mathrm{~K}$, air density is $0.0181 \mathrm{~kg} / \mathrm{m}^{3}$ and dynamic viscosity is $1.475 \times 10^{-5} \mathrm{~Pa} \cdot \mathrm{s}$.

According to the different Mach numbers, the vehicle is in different external flow field environments [7,19]. At the transonic speed stage (when the Mach number is between 0.6 and 1), compressibility effects such as flow choking becoming important. At the supersonic speed stage (Mach number between 1 and 3), depending on the specific shape of the aircraft, a shock wave may be produced in the airflow. At the high supersonic (when the Mach number is between 3 and 5) and hypersonic speed stage (when the Mach number is bigger than 5), aerodynamic heating becomes very important. The flight path of the RBCC scramjet-propelled vehicle spans all of the above stages; therefore, a specific piecewise analysis is needed. According to the Mach number of the flight path, the simulation scheme is divided into four stages. To ensure the reliability of the prediction results, the simulation parameters should be confirmed by validation tests at each stage.

For flows involving compressibility and heat transfer, three conservation equations for mass, momentum, and energy need to be solved. When the flow is turbulent, additional transport equations are also solved, adopting the one-equation RANS Spalart-Allmaras model, which is the most widely applied [20], and the two-equation RANS SST k-omega turbulence model [21]. The control-volume-based technique is used to discretize the above equations. Firstly, the external flow field model is divided into discrete control volumes using a computational grid. Secondly, the integration of equations on the individual control volumes to algebraic equations for the discrete dependent variables and conserved scalars is accomplished using an upwind scheme. Next, the above-discretized equations are linearized, and the resultant linear equation system is solved to yield variables. Two numerical solvers, a pressure-based solver and a density-based solver, were applied in this study. More details about these equations and the finite volume method could be found in Ref. [22].

\section{Validation Tests}

3.1. Transonic Stage

\subsubsection{Grid Strategy}

The experimental data in Ref. [23] are used to validate the simulation parameters at this stage, and the simulation external flow field model is as shown in Figure 2. The bold 
black dot is the $(0,0)$ point of the coordinate system. Line $\mathrm{f}$ is the wedge section, line $\mathrm{g}$ is the flat plate.

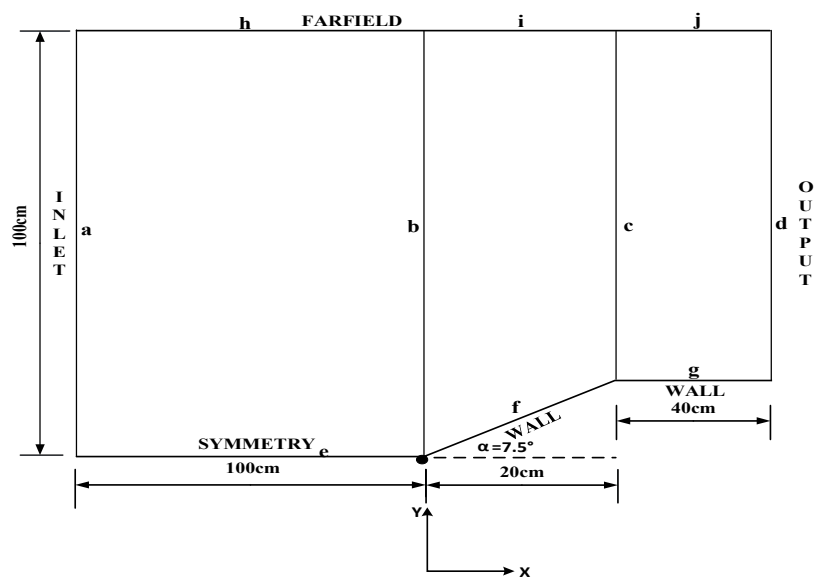

Figure 2. The external flow field simulation model for the transonic stage.

Turbulent flows are affected by the presence of walls; therefore, the accurate representation of the flow in the near-wall region determines the successful prediction of wall-bounded turbulent flows, and it is necessary to ensure the first layer cells of the boundary layer are in the sub-viscosity layer. The calculation of the height of the first layer cells of the boundary layer begins with the flow Reynolds number $\left(R_{e}\right)$ :

$$
R_{e}=\frac{\rho U L}{\mu}
$$

where $L$ is the characteristic length of the wedge, $\mu$ is the dynamic viscosity of the air, $\rho$ is the air density, and $U$ is the velocity of freestream. Considering that the simulation model is wedge-shaped, an empirical correlation formulation to estimate the skin friction coefficient $\left(C_{f}\right)$ is adopted, which is for the fully developed turbulent flow over a flat plate:

$$
C_{f}=\left[2 \log _{10}\left(R_{e}\right)-0.65\right]^{-2.3}
$$

Having computed the skin friction coefficient, the wall shear stress $\left(\tau_{W}\right)$ is calculated:

$$
\tau_{W}=\frac{1}{2} \rho U^{2} C_{f}
$$

After that, we can calculate the friction velocity $\left(u_{\tau}\right)$ from the wall shear stress $\left(\tau_{W}\right)$ :

$$
u_{\tau}=\left(\frac{\tau_{W}}{\rho}\right)^{0.5}
$$

The equation for $y^{+}$is:

$$
y^{+}=\frac{\rho y_{P} u_{\tau}}{\mu}
$$

Therefore, the height of the wall-adjacent cell centroid from the wall $\left(y_{P}\right)$ is:

$$
y_{P}=\frac{y^{+} \mu}{u_{\tau} \rho}
$$

Finally, the first height of the boundary layer cell $\left(y_{H}\right)$ is double $y_{P}$ :

$$
y_{H}=2 y_{P}
$$


The result of the first height of the boundary layer cell is an estimate and needs to be updated using information from the CFD analysis. In addition to calculating the $y_{H}$, the growth ratio $(r)$ normal to the wall and inflation layers $(N)$ may also be required by mesh generation, which allows the layers to inflate normally to the wall. For aerodynamic flows using RANS turbulence modeling, CFD often aims for $N=15-30$ through the thickness of the boundary layer. By adopting this criterion, we can calculate $\mathrm{r}$ normally to the wall, which is started by applying the formulation to estimate the boundary layer thickness, where $R_{e}$ is bigger than $5 \times 10^{5}$ :

$$
\delta=\frac{0.38 L}{R_{e}^{0.2}}
$$

For a given number of $r$ and $N$, we can calculate the total thickness of the inflation layers. Next, we match this to the boundary layer thickness $\delta$ to allow the inflation layers to cover the boundary layer thickness. Assume that the inflation layer has two layers, then the total thickness $\left(y_{T}\right)$ is:

$$
y_{T}=y_{H}+y_{H} r
$$

Similarly, the total thickness of four inflation layers is:

$$
y_{T}=y_{H}+y_{H} r+y_{H} r^{2}+y_{H} r^{3}
$$

Therefore, the total thickness of $N$ inflation layers is:

$$
y_{T}=\sum_{i=0}^{N-1} y_{H} r^{i}
$$

Equation (11) is the formula of a geometric series, which could be rewritten using the identity for convenience:

$$
\sum_{i=0}^{N-1} y_{H} r^{i}=y_{H} \frac{1-r^{N}}{1-r}
$$

Hence, the total thickness of the inflation layer is:

$$
y_{T}=y_{H} \frac{1-r^{N}}{1-r}
$$

Now, the error between the total thickness of the inflation layer $y_{T}$ and the thickness of the boundary layer $\delta$ is:

$$
e=y_{H} \frac{1-r^{N}}{1-r}-\delta
$$

Equation (14) is a function of the growth ratio $r$ and we need to find a value of $r$ to make the error equal to 0 , which is the total height of the inflation layer equal to the boundary layer thickness. The Newton-Raphson root-finding algorithm is adopted, and once the algorithm has converged, the solution $r$ is the maximum growth ratio. Because, in mesh generators, the $r$ is always greater than 1 and less than 2, the initial guess of 1 and 2 could be used to bound the root-finding algorithm to accelerate the convergence.

Three different Mach numbers, 0.768, 0.817. and 0.86 were applied, respectively, in the validation tests at the subsonic stage. The static temperature of freestream $T$ was $300 \mathrm{~K}$ and the dynamic viscosity $\mu$ was $1.7894 \times 10^{-5} \mathrm{~Pa} \cdot \mathrm{s}$; the density of air was ideal-gas, the specific heat at a constant air pressure was $1006.43 \mathrm{j} / \mathrm{kg}-\mathrm{k}$, and the characteristic length $c$ was $0.59696 \mathrm{~m}$. Initially, $y^{+}$was 5 to ensure the first layer cells of the boundary layer were in the sub-viscosity layer, and $y_{H}$ was $1.53 \times 10^{-5}$, according to Equations (1)-(7). Next, the CFD analysis showed that the maximum value of $y^{+}$at the WALL surface reached 6.5. The simulation tests showed that the $y^{+}$value of 1 could guarantee that the first layer cells of the boundary layer are in the sub-viscosity layer during the simulation process. The turbulent viscosity ratio (TVR) was adopted to evaluate whether the boundary layer profile was captured well. Figure 3 shows the corresponding plots of the TVR for the mesh 
with $y^{+}=1$ and $N=20$, since the $y^{+}$value is 1 , which means presence within the laminar sub-layer, and absence of turbulent viscosity. As the mesh moved through the buffer region and into the logarithmic region, the TVR value increased, and the maximum value occurred near the middle of the boundary layer. Subsequently, the turbulence gradually dissipated as the mesh approached the free stream condition, which was expected. Therefore, the values of $y^{+}$and $\mathrm{N}$ were sufficient, so we could calculate the maximum growth ratio $\mathrm{r}$ by Equation (14). The first layer height $y_{H}$ and the maximum growth ratio were $\left(1.49 \times 10^{-6}\right.$, $1.42),\left(1.38 \times 10^{-6}, 1.42\right)$ and $\left(8.42 \times 10^{-6}, 1.34\right)$ respectively.

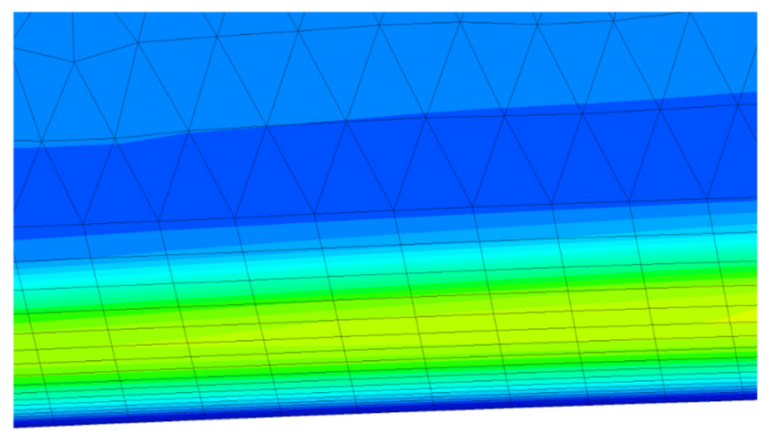

Figure 3. Yplus of 1 with 20 inflation layers.

To determine the best domain size, computational region analysis was performed. For this purpose, three sizes were chosen, as shown in Figure 4a [24]. The INLET boundary contained line a, the OUTPUT boundary contained line $d$, the FARDIELD boundary contained lines $h, i$, and $j$, the SYMMETRY boundary contained line e, and the WALL boundary contained lines $\mathrm{f}$ and $\mathrm{g}$. Figure $4 \mathrm{~b}$ offers a close view of the grids near the WALL region. Taking the numerical simulation adopting freestream Mach number of 0.768 and the Spalart-Allmaras model as an example, the values of the local Mach number $m$, the pressure coefficient $\left(c_{p}\right)$, and the temperature are as shown in Table 1 , where $x$ is the $X$-axis location, and the computational domain with $8 \mathrm{c}$ was chosen for low errors. Further, to be sure of grid independency, three levels of different mesh were applied. As can be seen in Table 2, it is clear that the values of $m$ at 480,000 were better; therefore, the mesh with 480,000 cells was selected.

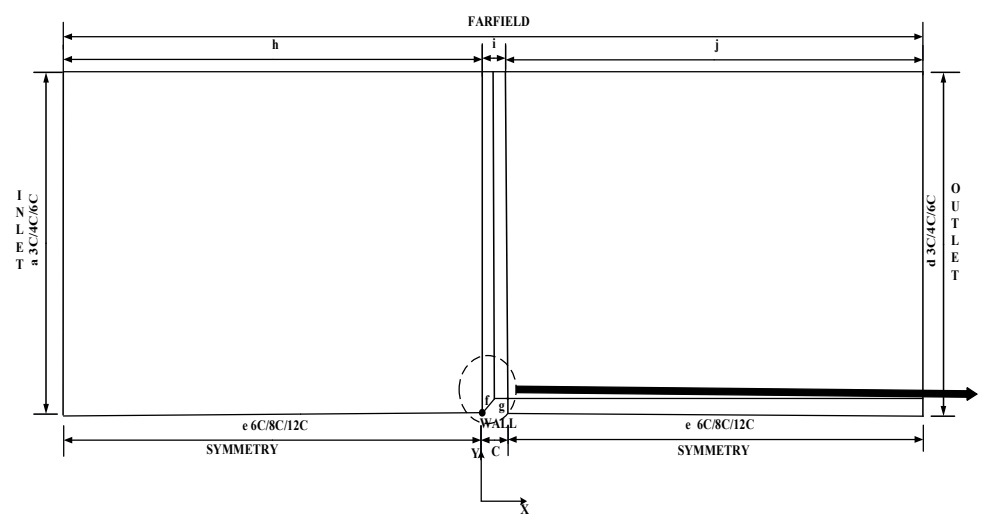

(a)

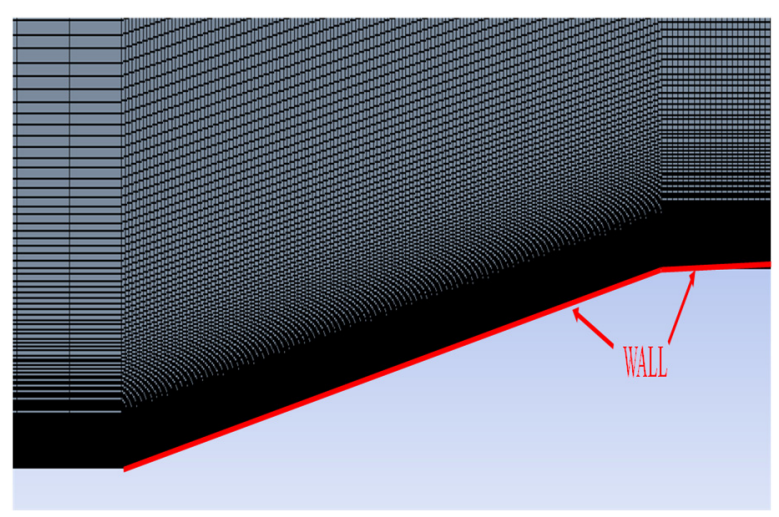

(b)

Figure 4. (a) computational domain; (b) close view of grids in and near the WALL region. 
Table 1. Computational domain independency study of three levels of sizes with error ratios.

\begin{tabular}{|c|c|c|c|c|c|c|c|c|c|c|c|c|c|c|c|c|c|c|}
\hline \multirow{4}{*}{$\begin{array}{c}\begin{array}{c}\text { Computational } \\
\text { Domains }\end{array} \\
6\end{array}$} & \multicolumn{18}{|c|}{$\begin{array}{c}\mathrm{x} / \mathrm{c} \\
\left(\mathrm{m}, \mathrm{c}_{\mathrm{p}}, \text { Temperature and Error Ratio) }\right.\end{array}$} \\
\hline & \multicolumn{3}{|c|}{0} & \multicolumn{3}{|c|}{0.2} & \multicolumn{3}{|c|}{0.4} & \multicolumn{3}{|c|}{0.6} & \multicolumn{3}{|c|}{0.8} & \multicolumn{3}{|c|}{1} \\
\hline & 0.3745 & 0.6719 & 308.5 & 0.59013 & 0.4052 & 290.7 & 0.63756 & 0.3451 & 290.1 & 0.67321 & 0.2939 & 284.4 & 0.71826 & 0.2351 & 286.7 & 0.8773 & 0.00459 & 287.7 \\
\hline & $15.49 \%$ & 12.54 & / & $14.25 \%$ & $13.09 \%$ & / & $13.52 \%$ & $11.68 \%$ & / & $13.29 \%$ & $11.95 \%$ & / & $13.8 \%$ & $12.13 \%$ & I & $10.49 \%$ & $10.4 \%$ & / \\
\hline \multirow{2}{*}{8} & 0.3793 & 0.6819 & 321.5 & 0.59774 & 0.4112 & 302.7 & 0.64396 & 0.3497 & 302.8 & 0.68116 & 0.2971 & 300.7 & 0.72441 & 0.239 & 301.8 & 0.886 & 0.00465 & 302.1 \\
\hline & 14.41 & 11.24 & / & $13.15 \%$ & $11.81 \%$ & / & $12.65 \%$ & $10.5 \%$ & / & $12.26 \%$ & $10.99 \%$ & / & $13.06 \%$ & $10.67 \%$ & / & $9.58 \%$ & $9.23 \%$ & / \\
\hline 12 & 0.3779 & 0.6769 & 329.2 & 0.59644 & 0.4097 & 311.3 & 0.64085 & 0.3477 & 309.1 & 0.67843 & 0.2964 & 310.2 & 0.7211 & 0.2371 & 310.2 & 0.882 & 0.00463 & 311.2 \\
\hline
\end{tabular}

Table 2. Grid independency study of three levels of different mesh with error ratios.

\begin{tabular}{|c|c|c|c|c|c|c|c|c|c|c|c|c|c|c|c|c|c|c|}
\hline \multirow{2}{*}{ Mesh (Cells) } & \multicolumn{18}{|c|}{$\begin{array}{c}\mathrm{x} / \mathrm{c} \\
\left(\mathrm{m}, \mathrm{c}_{\mathrm{p}}, \text { Temperature and Error Ratio) }\right.\end{array}$} \\
\hline & \multicolumn{3}{|c|}{0} & \multicolumn{3}{|c|}{0.2} & \multicolumn{3}{|c|}{0.4} & \multicolumn{3}{|c|}{0.6} & \multicolumn{3}{|c|}{0.8} & \multicolumn{3}{|c|}{1} \\
\hline \multirow{2}{*}{210,000} & 0.3793 & 0.6819 & 321.5 & 0.59774 & 0.4112 & 302.7 & 0.64396 & 0.3497 & 302.8 & 0.68116 & 0.2971 & 300.7 & 0.72441 & 0.239 & 301.8 & 0.886 & 0.00465 & 302.1 \\
\hline & $14.41 \%$ & $11.24 \%$ & / & $13.15 \%$ & $11.8 \%$ & / & $12.65 \%$ & $10.5 \%$ & / & $12.26 \%$ & $10.99 \%$ & / & $13.06 \%$ & $10.67 \%$ & / & $9.58 \%$ & $9.23 \%$ & / \\
\hline \multirow{2}{*}{480,000} & 0.4025 & 0.7032 & 330.9 & 0.62447 & 0.4262 & 312.3 & 0.67889 & 0.3636 & 312.3 & 0.71274 & 0.3091 & 310.6 & 0.75994 & 0.2481 & 310.9 & 0.915 & 0.00481 & 311.7 \\
\hline & $9.17 \%$ & $8.46 \%$ & / & $9.26 \%$ & $8.59 \%$ & / & $7.91 \%$ & $6.95 \%$ & / & $8.2 \%$ & $7.39 \%$ & / & $8.79 \%$ & $7.27 \%$ & / & $6.7 \%$ & $6.10 \%$ & / \\
\hline \multirow{2}{*}{680,000} & 0.3978 & 0.6919 & 331.2 & 0.62047 & 0.4198 & 312.7 & 0.66488 & 0.3591 & 313.1 & 0.70963 & 0.3041 & 308.2 & 0.743 & 0.2438 & 310.2 & 0.901 & 0.00475 & 312.5 \\
\hline & $10.23 \%$ & $9.93 \%$ & / & $9.84 \%$ & $9.96 \%$ & / & $9.81 \%$ & $8.1 \%$ & / & $8.60 \%$ & $8.89 \%$ & / & $10.78 \%$ & $8.87 \%$ & / & $8.06 \%$ & $7.27 \%$ & / \\
\hline
\end{tabular}




\subsubsection{Numerical Method}

At the transonic stage, the pressure-based solver was used with a coupled algorithm [25]. The second-order upwind interpolation scheme was selected for the density [26]. The gradients were computed according to the least-squares cell-based method. For preventing spurious oscillations, a gradient limiter was adopted, which used the Minmod function [17] to limit and clip the reconstructed solution overshoots and undershoots on the cell faces. The second-order scheme was used for interpolating the pressure values at the faces, which reconstructed the face pressure using a central differencing scheme. The validation parameters of the convergence numerical results were as shown in Table 3.

Table 3. Validation parameters of convergence results at the transonic stage.

\begin{tabular}{|c|c|c|}
\hline Validation Parameters & & \\
\hline Solver & $\begin{array}{l}\text { Pressure-based with coupled } \\
\text { algorithm }\end{array}$ & $\begin{array}{l}\text { Pressure-based with coupled } \\
\text { algorithm }\end{array}$ \\
\hline Turbulence Models & SST k-omega & Spalart-Allmaras \\
\hline Materials & $\begin{array}{c}\text { Density: Ideal-gas } \\
\text { Viscosity: } 1.7894 \times 10^{-5} \mathrm{~Pa} \cdot \mathrm{s} \\
\mathrm{C}_{\mathrm{p}}(\mathrm{j} / \mathrm{kg}-\mathrm{k}): 1006.43\end{array}$ & $\begin{array}{c}\text { Density: Ideal-gas } \\
\text { Viscosity: } 1.7894 \times 10^{-5} \mathrm{~Pa} \cdot \mathrm{s} \\
\mathrm{C}_{\mathrm{p}}(\mathrm{j} / \mathrm{kg}-\mathrm{k}): 1006.43\end{array}$ \\
\hline Initial conditions & $\begin{array}{c}\text { Mach number: } 0.768 / 0.817 / 0.86 \\
\text { Static temperature: } 300 \mathrm{~K}\end{array}$ & $\begin{array}{c}\text { Mach number: } 0.768 / 0.817 / 0.86 \\
\text { Static temperature: } 300 \mathrm{~K}\end{array}$ \\
\hline Boundary conditions & $\begin{array}{l}\text { INPUT: pressure far field } \\
\text { FARFIELD: pressure far field } \\
\text { OUTPUT: pressure outlet } \\
\text { SYMMETRY: symmetry } \\
\text { WALL: no-slip, isothermal }\end{array}$ & $\begin{array}{l}\text { INPUT: pressure far field } \\
\text { FARFIELD: pressure far field } \\
\text { OUTPUT: pressure outlet } \\
\text { SYMMETRY: symmetry } \\
\text { WALL: no-slip, isothermal }\end{array}$ \\
\hline
\end{tabular}

\subsubsection{Simulation Parameters}

Figure 5 demonstrates the distributions of $m$ under three different Mach numbers of freestream $M$, where the $X$-axis was the ratio between $x$ and $c$ and the $Y$-axis was the value of $m$. EXP represents the experimental data, SST and SA represent the simulation results based on SST k-omega and Spalart-Allmaras, respectively. The overall tracking effect of the simulation data on the experiment data was good. At $M=0.768$, the average error rate of SST k-omega was $9.69 \%$, and that of Spalart-Allmaras was $8.34 \%$. The variance of SST k-omega error was 0.000368 , and that of Spalart-Allmaras is 0.000122. At $M=0.817$, the average error rate of SST k-omega was $9.52 \%$, and that of Spalart-Allmaras was $8.18 \%$. The variance of SST k-omega error was 0.00035 , and that of Spalart-Allmaras was 0.000152. At $M=0.86$, the average error rate of SST k-omega was $10.14 \%$, and that of Spalart-Allmaras was $8.52 \%$. The variance of SST k-omega error was 0.000359, and that of Spalart-Allmaras was 0.000284. The total mean error rates were $9.78 \%$ for SST and $8.35 \%$ for Spalart-Allmaras. In general, the trend of the simulation results was in good agreement with the experimental data, and of the two models, the Spalart-Allmaras simulation results were better than those of SST k-omega at the transonic stage.

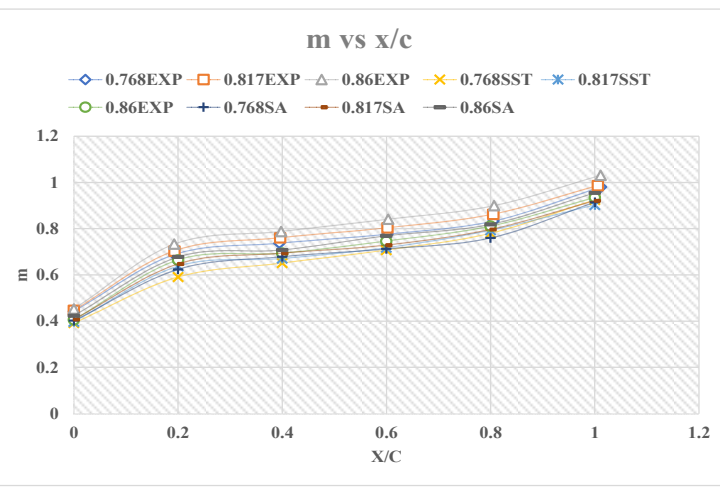

Figure 5. Local Mach number versus $x$ / $c$ for different Mach numbers of freestream. 
In conclusion, the mesh with the value of $y^{+}$as $1,=$ the turbulence model applying Spalart-Allmaras and the pressure-based solver, adopting a coupled algorithm, is preferred at the transonic stage.

\subsection{Supersonic Stage}

\subsubsection{Grid Strategy}

The experimental data in Ref. [27] were used to validate the simulation parameters at this stage. Given the existence of the shock wave in the airflow, the value of the shock wave angle was estimated firstly. The Mach number $M$ was 2.85 and the wedge angle $\alpha$ is $30^{\circ}$, which meets the Equation (15), where $\gamma=1.4$ :

$$
\alpha<\frac{4}{3 \sqrt{3}(\gamma+1)} \frac{\left(M^{2}-1\right)^{3 / 2}}{M^{2}}
$$

The shock angle $s$ was $54^{\circ}$, which was calculated by Equation (16):

$$
\cot \alpha=\tan s\left[\frac{(r+1) M^{2}}{2\left(M^{2}(\sin s)^{2}-1\right.}-1\right]
$$

Next, we established and divided the external flow field model for the simulation, as shown in Figure 6. The bold black dot is the $(0,0)$ point of the coordinate system. Lines o and $q$ are the flat plate and line $p$ is the wedge section. The bold black square point is the origin of the wedge section.

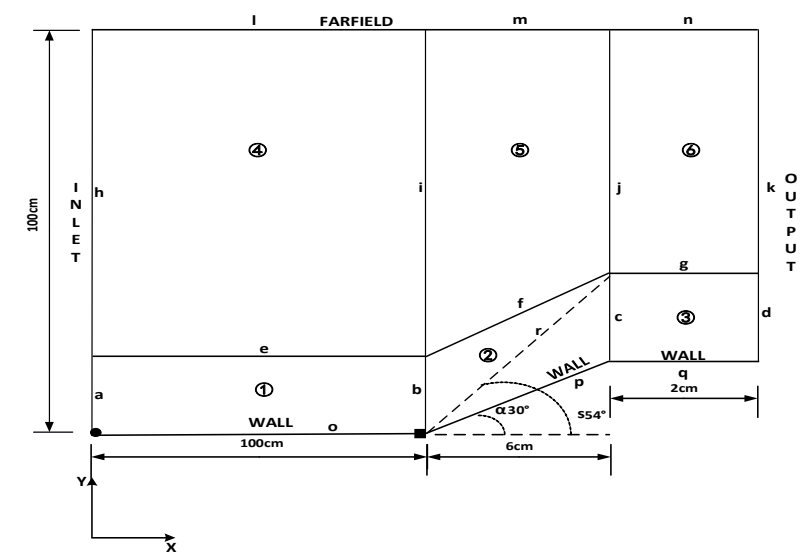

Figure 6. The external flow field simulation model for the supersonic stage.

At the supersonic stage, the total temperature of the freestream $T_{t}$ was $270 \mathrm{~K}$ and the total pressure of the freestream $p_{t}$ was $1.7 \mathrm{~atm}$. The static temperature of the freestream $T$ was calculated by Equation (17) and $T$ was $102.88 \mathrm{~K}$ :

$$
\frac{T_{t}}{T}=1+\frac{\gamma-1}{2} M^{2}
$$

The static pressure of the freestream $p$ was calculated by Equation (18) and $p$ was $5881 \mathrm{~Pa}$ :

$$
\frac{p_{t}}{p}=\left(1+\frac{\gamma-1}{2} M^{2}\right)^{\frac{\gamma}{\gamma-1}}
$$

The speed of sound $C_{a i r}$ was calculated by Equation (19) and $C_{a i r}$ was $203.36348 \mathrm{~m} / \mathrm{s}$ :

$$
C_{\text {air }}=20.05 \sqrt{T}
$$


The Mach number $M$ was 2.85 and the velocity of the freestream $U$ was $579.5859 \mathrm{~m} / \mathrm{s}$. The corresponding unit Reynolds number of the freestream was $18 \times 10^{6}$, the characteristic length $L$ was $1.08 \mathrm{~m}$, the density of air was ideal-gas, the specific heat at constant air pressure was $1006.43 \mathrm{j} / \mathrm{kg}-\mathrm{k}$, and the viscosity adopted three-coefficient Sutherland Law. Initially, we referred to the value of $y^{+}$at the transonic stage to estimate $y_{H} 3.25 \times 10^{-6}$, while the test results showed that the maximum $y^{+}$of the wall surface exceeded 1 during the simulation. As described in the previous section, considering the maximum $y^{+}$of wall surface during the CFD simulation and the boundary layer profile through TVR, the $y^{+}$ value was 0.8 and the $y_{H}$ value was $2.5 \times 10^{-6}$.

To determine the best domain size, a computational region analysis is performed. For this purpose, three sizes were chosen, as shown in Figure 7a [24]. The INLET boundary contains line $a$ and $h$, the OUTPUT boundary contains lines $d$ and $k$, the FARDIELD boundary contains lines $1, \mathrm{~m}$, and $\mathrm{n}$ and the WALL boundary contains lines $\mathrm{o}, \mathrm{p}$, and $\mathrm{q}$. Because of the shock wave, in order to obtain more accurate results, more attention was needed for the grids near the shock wave regions. Figure $7 \mathrm{~b}$ demonstrates the close view of the grids near the shock wave region. Taking the SST k-omega model as an example, the values of the ratio between the wall surface pressure $p$ and $p_{t}$, and temperature are as shown in Table 4, where $x$ is the distance to the origin point of the wedge section, and the computational domain with $8 \mathrm{c}$ was chosen for low ratio errors. Next, three levels of different mesh were applied to ensure grid independency. From Table 5, the mesh with 520,000 cells was applied at this stage.

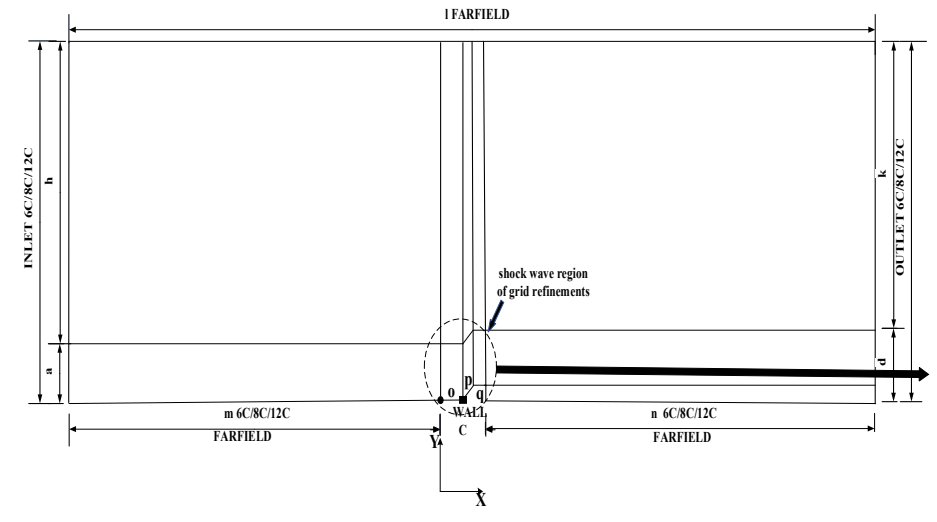

(a)

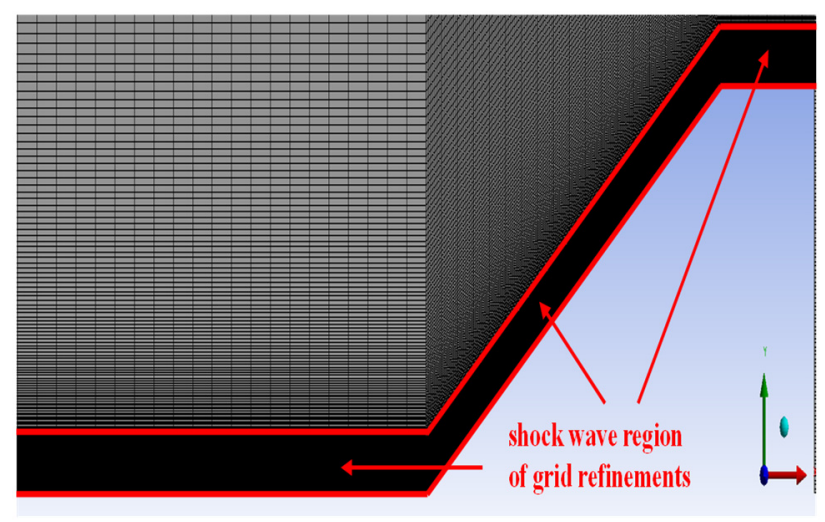

(b)

Figure 7. (a) computational domain; (b) close view of grids in near shock wave region.

Table 4. Computational domain independency study of three levels of sizes with error ratios.

\begin{tabular}{|c|c|c|c|c|c|c|c|c|c|c|}
\hline \multirow{4}{*}{$\begin{array}{c}\text { Computational } \\
\text { Domain } \\
6 c\end{array}$} & \multicolumn{10}{|c|}{$\begin{array}{c}x(\mathrm{~m}) \\
\left(\mathrm{p} / \mathrm{p}_{\mathrm{t}}, \text { Temperature and Error Ratio) }\right.\end{array}$} \\
\hline & \multicolumn{2}{|c|}{0} & \multicolumn{2}{|c|}{0.02} & \multicolumn{2}{|c|}{0.04} & \multicolumn{2}{|c|}{0.06} & \multicolumn{2}{|c|}{0.08} \\
\hline & 0.0873 & 241.887 & 0.1088 & 239.475 & 0.1372 & 242.097 & 0.0451 & 242.643 & 0.0348 & 243.842 \\
\hline & $10.33 \%$ & I & $10.78 \%$ & 1 & $9.68 \%$ & / & $12.1 \%$ & I & $11.26 \%$ & / \\
\hline \multirow[b]{2}{*}{$8 c$} & 0.0861 & 252.149 & 0.1103 & 252.941 & 0.1396 & 253.461 & 0.0443 & 254.013 & 0.0353 & 254.314 \\
\hline & $8.81 \%$ & / & $9.55 \%$ & / & $8.1 \%$ & / & $10.11 \%$ & / & $9.98 \%$ & / \\
\hline \multirow{2}{*}{$12 \mathrm{c}$} & 0.0868 & 259.411 & 0.1098 & 258.115 & 0.1389 & 257.329 & 0.0446 & 259.227 & 0.0351 & 257.669 \\
\hline & $9.7 \%$ & / & $9.96 \%$ & / & $8.56 \%$ & / & $10.86 \%$ & / & $10.49 \%$ & / \\
\hline
\end{tabular}


Table 5. Grid independency study of three levels of different mesh with error ratios.

\begin{tabular}{|c|c|c|c|c|c|c|c|c|c|c|}
\hline \multirow{2}{*}{ Mesh (Cells) } & \multicolumn{10}{|c|}{$\begin{array}{c}x(m) \\
\left(p / p_{t}, \text { Temperature and Error Ratio) }\right.\end{array}$} \\
\hline & \multicolumn{2}{|c|}{0} & \multicolumn{2}{|c|}{0.02} & \multicolumn{2}{|c|}{0.04} & \multicolumn{2}{|c|}{0.06} & \multicolumn{2}{|c|}{0.08} \\
\hline \multirow{2}{*}{270,000} & 0.0861 & 252.149 & 0.1103 & 252.941 & 0.1396 & 253.461 & 0.0443 & 254.013 & 0.0353 & 254.314 \\
\hline & $8.81 \%$ & / & $9.55 \%$ & / & $8.10 \%$ & / & $10.11 \%$ & / & $9.98 \%$ & / \\
\hline \multirow{2}{*}{520,000} & 0.0850 & 262.052 & 0.1118 & 262.631 & 0.1412 & 263.803 & 0.0439 & 264.211 & 0.0358 & 264.702 \\
\hline & $7.44 \%$ & / & $8.28 \%$ & / & $7.08 \%$ & / & $9.33 \%$ & / & $8.83 \%$ & / \\
\hline \multirow{2}{*}{720,000} & 0.0853 & 264.043 & 0.1117 & 260.574 & 0.1405 & 264.887 & 0.0441 & 262.059 & 0.0356 & 265.413 \\
\hline & $7.80 \%$ & / & $8.40 \%$ & / & $7.51 \%$ & / & $9.61 \%$ & / & $9.22 \%$ & / \\
\hline
\end{tabular}

\subsubsection{Numerical Method}

At the supersonic stage, the numerical method is similar to the transonic stage. The validation parameters of the convergence numerical results are shown in Table 6.

Table 6. Validation parameters of convergence results at the supersonic stage.

\begin{tabular}{|c|c|c|}
\hline Validation Parameters & & \\
\hline Solver & $\begin{array}{l}\text { Pressure-based with coupled } \\
\text { algorithm }\end{array}$ & $\begin{array}{l}\text { Pressure-based with coupled } \\
\text { algorithm }\end{array}$ \\
\hline Models & SST k-omega & Spalart-Allmaras \\
\hline Materials & $\begin{array}{c}\text { Density: Ideal-gas } \\
\text { Viscosity: Sutherland law } \\
\mathrm{C}_{\mathrm{p}}(\mathrm{j} / \mathrm{kg}-\mathrm{k}): 1006.43\end{array}$ & $\begin{array}{c}\text { Density: Ideal-gas } \\
\text { Viscosity: Sutherland law } \\
\mathrm{C}_{\mathrm{p}}(\mathrm{j} / \mathrm{kg}-\mathrm{k}): 1006.43\end{array}$ \\
\hline Initial conditions & $\begin{array}{c}\text { Mach number: } 2.85 \\
\text { Static pressure: } 5881 \mathrm{~Pa} \\
\text { Static Temperature: } 102.88 \mathrm{~K}\end{array}$ & $\begin{array}{c}\text { Mach number: } 2.85 \\
\text { Static pressure: } 5881 \mathrm{~Pa} \\
\text { Static Temperature: } 102.88 \mathrm{~K}\end{array}$ \\
\hline Boundary conditions & $\begin{array}{c}\text { INPUT: pressure far field } \\
\text { FARFIELD: pressure far field } \\
\text { OUTPUT: pressure outlet } \\
\text { WALL: no-slip, isothermal, } 300 \mathrm{~K}\end{array}$ & $\begin{array}{c}\text { INPUT: pressure far field } \\
\text { FARFIELD: pressure far field } \\
\text { OUTPUT: pressure outlet } \\
\text { WALL: no-slip, isothermal, } 300 \mathrm{~K}\end{array}$ \\
\hline
\end{tabular}

\subsubsection{Simulation Parameters}

Figure 8 shows the wall surface pressure distributions from the experiment and the simulation, where the $X$-axis $x$ is the distance to the original point of the wedge section and the $Y$-axis is the ratio between the wall surface pressure and the total pressure of the freestream. The overall tracking effect of the simulation data on the experiment data was acceptable. The simulation errors of the two models were very close at the upper stream of the wedge section. At the wedge section, where $x$ was bigger than 0 , the mean error rate of SST k-omega data was $4.76 \%$, and that of Spalart-Allmaras was $5.19 \%$. The variance of SST k-omega simulation error was 0.001043, and that of Spalart-Allmaras was 0.003091 . Figure 9 indicates the density profiles at $\mathrm{x}=0$ from the experiment and the simulation, the $X$-axis is the ratio between local density and the freestream density, and the $Y$-axis is the y location. The average error rate of the SST k-omega data was $7.92 \%$, and that of Spalart-Allmaras was $10.04 \%$. The variance of the SST k-omega simulation error was 0.00307 , and that of Spalart-Allmaras was 0.003417. In general, the trend of the simulation results was in good agreement with the experimental data, and the SST k-omega simulation results were better than those of Spalart-Allmaras at the supersonic stage. 


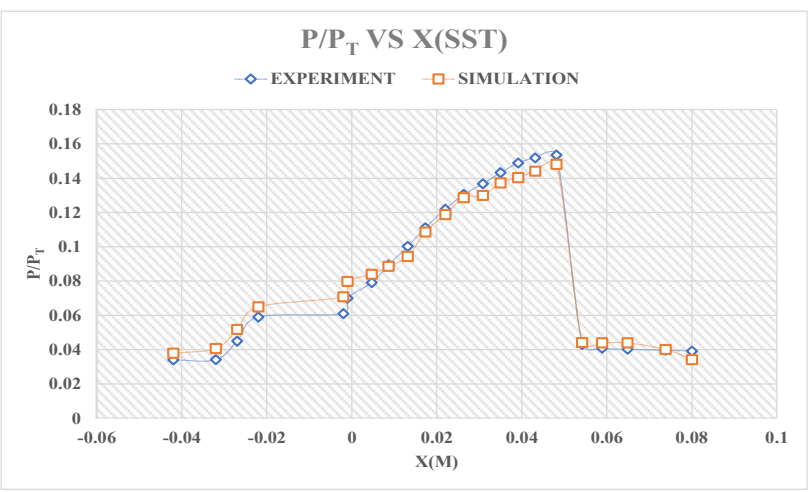

(a)

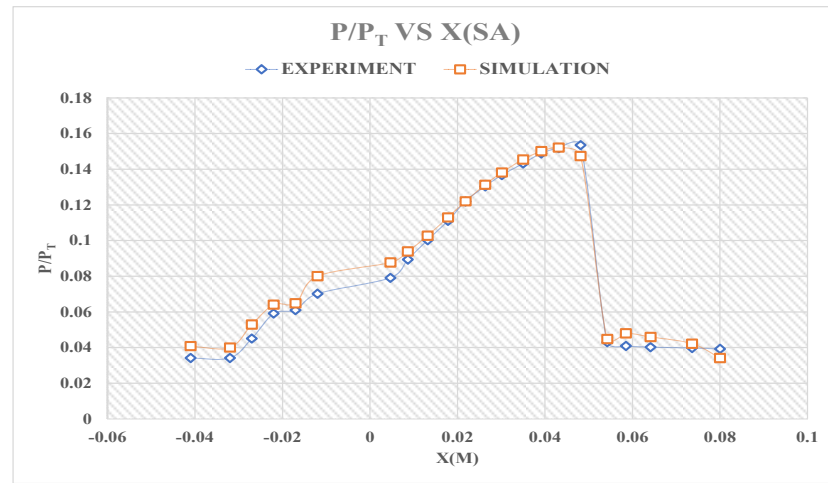

(b)

Figure 8. (a) surface-pressure distributions from experiment and SST k-omega simulation; (b) surfacepressure distributions from experiment and Spalart-Allmaras simulation.

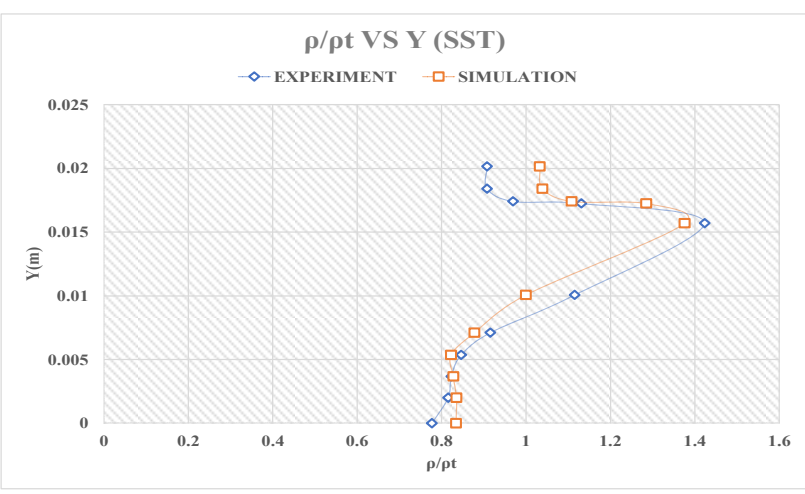

(a)

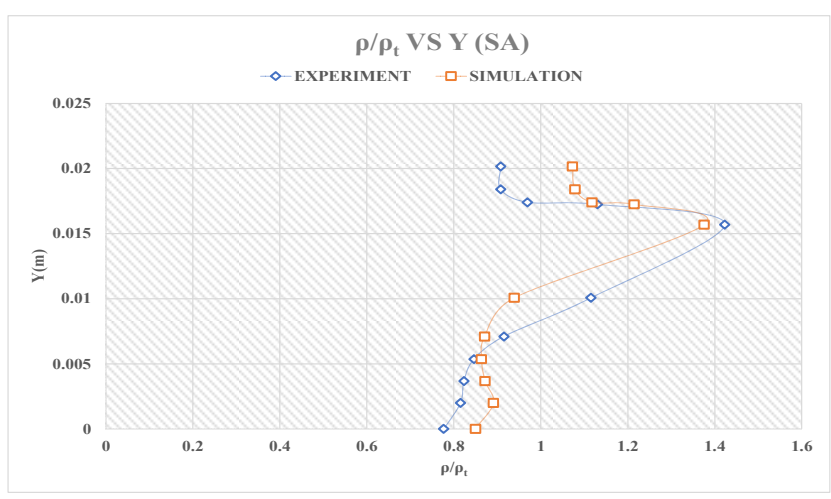

(b)

Figure 9. (a) density profile at $x=0$ from experiment and SST k-omega simulation; (b) density profile at $x=0$ from experiment and Spalart-Allmaras simulation.

\subsection{High Supersonic Stage}

\subsubsection{Grid Strategy}

The experimental data in Ref. [28] were used to validate the simulation parameters at this stage. The Mach number $M$ was 5 and the wedge angle $\alpha$ was $15^{\circ}$. The shock angle $\mathrm{s}$ was $24.32^{\circ}$, which was calculated by Equation (16). Next, we established and divided the external flow field model for the simulation, as shown in Figure 10. The bold black dot is the $(0,0)$ point of the coordinate system. Line $\mathrm{m}$ is the flat plate and line $\mathrm{n}$ is the wedge section. The bold black square point is the origin of the wedge section. $L$ is the distance between the flat plate's leading edge and the wedge section origin, which was $0.25 \mathrm{~m}$. 


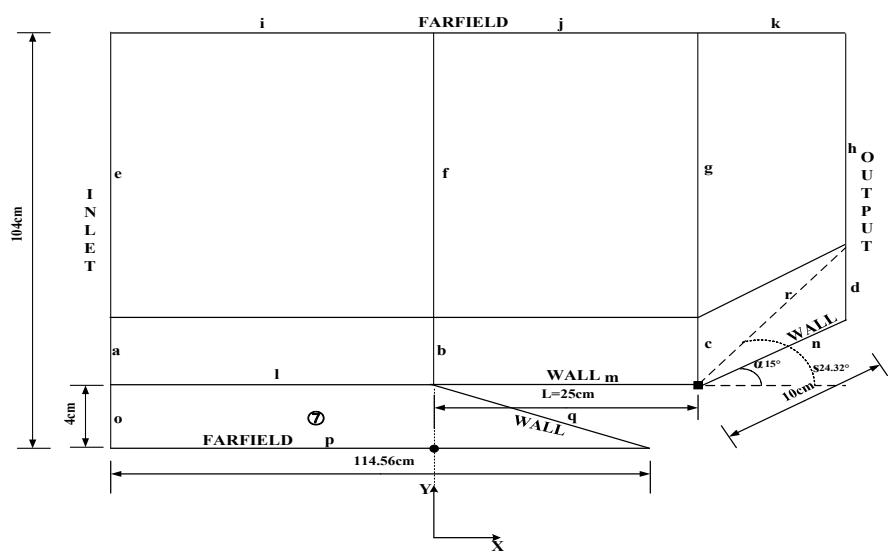

Figure 10. The external flow field simulation model for the high supersonic stage.

At the high supersonic stage, the total temperature of the freestream $T_{t}$ was $475 \mathrm{~K}$ and the total pressure of the freestream $p_{t}$ was $4.5 \times 10^{5} \mathrm{~Pa}$. The thermal conditions at the wall were $T_{w}=100 \mathrm{~K}$ leading to a ratio $T_{W} / T_{r}=0.24$ and $T_{w}=290 \mathrm{~K}$ leading to a ratio $T_{W} / T_{r}=0.72$, where $T_{r}$ is the recovery temperature. The static temperature of the freestream $T$ was calculated by Equation (17), and $T$ was $79.17 \mathrm{~K}$; the static pressure of the freestream $p$ was calculated by Equation (18), and $p$ is $850.5173 \mathrm{~Pa}$; the speed of sound $C_{a i r}$ was calculated by Equation (19), and $C_{a i r}$ was $178.3999 \mathrm{~m} / \mathrm{s}$. The Mach number $M$ was 5 and the velocity of the freestream $U$ was $891.99969 \mathrm{~m} / \mathrm{s}$. The density of air was ideal-gas, the specific heat at constant air pressure was $1006.43 \mathrm{j} / \mathrm{kg}-\mathrm{k}$, and the viscosity adopted three-coefficient Sutherland Law. The corresponding unit Reynolds number of the freestream was $6 \times 10^{6}$ and the characteristic length $c$ was about $0.34659 \mathrm{~m}$. At this stage, shock waves occurred and play important roles that affected the simulation. As in the previous stage, the computational region analysis was performed and three sizes were chosen, as shown in Figure 11a [24]. The INLET boundary contains lines a, e and o, the OUTPUT boundary contains lines $d$ and $h$, the FARDIELD boundary contains lines $i, j, k$, and $\mathrm{p}$, and the WALL boundary contains lines $\mathrm{m}, \mathrm{n}$, and $\mathrm{q}$. Figure $11 \mathrm{~b}$ shows the close view of the refined mesh near the shock wave region. Taking the SST k-omega model at $T_{W}=290 \mathrm{~K}$ as an example, the values of the wall pressure coefficient and wall Stanton number (st) were as shown in Table 7 , where $\mathrm{x}$ is the $X$-axis location, and the computational domain with $8 \mathrm{c}$ was chosen for low ratio errors. Further, three levels of different mesh were applied to be sure of grid independency and, from Table 8, the mesh with 540,000 cells was preferred.

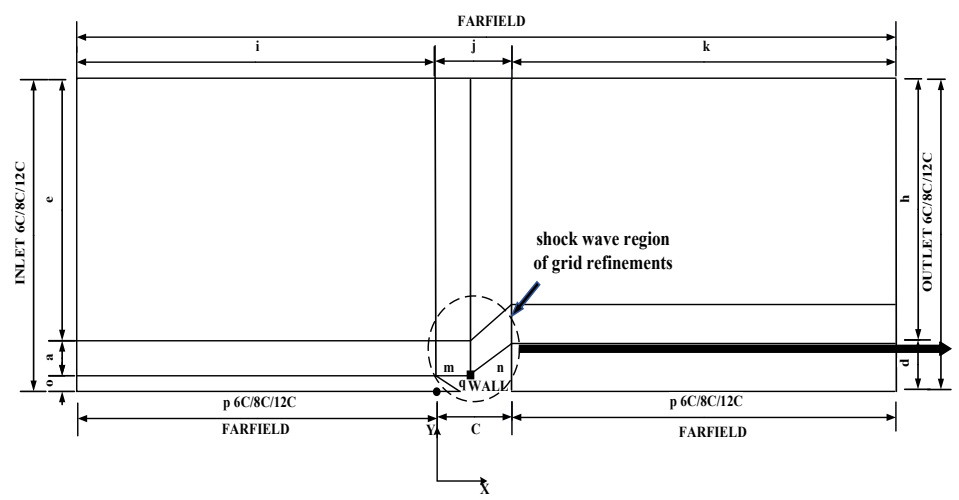

(a)

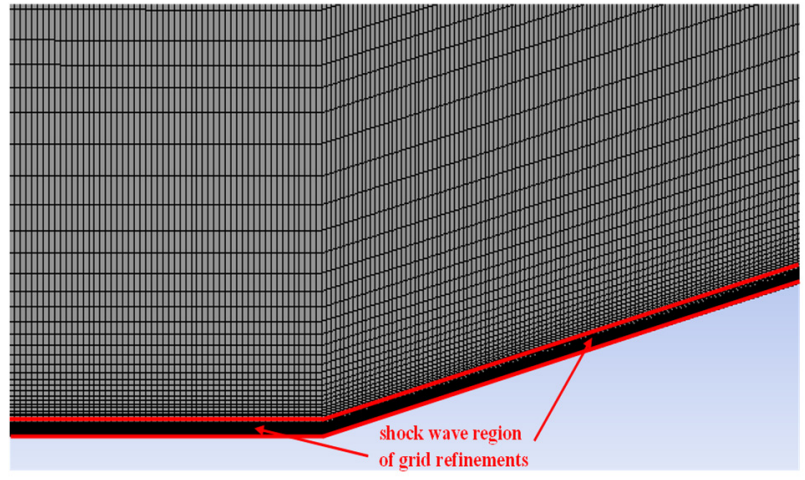

(b)

Figure 11. (a) computational domain; (b) close view of grids in near shock wave region. 
Table 7. Computational domain independency study of three levels of sizes with error ratios.

\begin{tabular}{|c|c|c|c|c|c|c|c|c|c|c|c|c|}
\hline \multirow{4}{*}{$\begin{array}{c}\text { Computational } \\
\text { Domains } \\
6 c\end{array}$} & \multicolumn{12}{|c|}{$\begin{array}{c}x / L \\
\left(c_{p}, \text { st and Error Ratio) }\right.\end{array}$} \\
\hline & \multicolumn{2}{|c|}{1.1} & \multicolumn{2}{|c|}{1.15} & \multicolumn{2}{|c|}{1.175} & \multicolumn{2}{|c|}{1.19} & \multicolumn{2}{|c|}{1.21} & \multicolumn{2}{|c|}{1.23} \\
\hline & 0.2193 & 0.001419 & 0.2286 & 0.001370 & 0.2201 & 0.001338 & 0.2216 & 0.001279 & 0.2230 & 0.001247 & 0.2229 & 0.001233 \\
\hline & $5.96 \%$ & $6.75 \%$ & $7.10 \%$ & $8.30 \%$ & $9.01 \%$ & $10.03 \%$ & $13.75 \%$ & $14.23 \%$ & $15.03 \%$ & $15.99 \%$ & $15.07 \%$ & $16.34 \%$ \\
\hline \multirow[b]{2}{*}{$8 c$} & 0.2173 & 0.001437 & 0.2261 & 0.001386 & 0.2226 & 0.001352 & 0.2246 & 0.001295 & 0.2254 & 0.001259 & 0.2253 & 0.001248 \\
\hline & $4.99 \%$ & $5.56 \%$ & $5.93 \%$ & $7.23 \%$ & $7.98 \%$ & $9.09 \%$ & $12.58 \%$ & $13.15 \%$ & $14.12 \%$ & $15.18 \%$ & $14.16 \%$ & $15.32 \%$ \\
\hline \multirow{2}{*}{$12 c$} & 0.2178 & 0.001431 & 0.2266 & 0.001381 & 0.2221 & 0.001347 & 0.2244 & 0.001290 & 0.2248 & 0.001255 & 0.2245 & 0.001245 \\
\hline & $5.24 \%$ & $5.96 \%$ & $6.17 \%$ & $7.56 \%$ & $8.18 \%$ & $9.43 \%$ & $12.66 \%$ & $13.49 \%$ & $14.35 \%$ & $15.54 \%$ & $14.46 \%$ & $15.53 \%$ \\
\hline
\end{tabular}

Table 8. Grid independency study of three levels of different mesh with error ratios.

\begin{tabular}{|c|c|c|c|c|c|c|c|c|c|c|c|c|}
\hline \multirow{4}{*}{$\begin{array}{c}\begin{array}{c}\text { Mesh } \\
\text { (Cells) }\end{array} \\
280,000\end{array}$} & \multicolumn{12}{|c|}{$\begin{array}{c}x / L \\
\left(c_{p}, \text { st and Error Ratio) }\right.\end{array}$} \\
\hline & \multicolumn{2}{|c|}{1.1} & \multicolumn{2}{|c|}{1.15} & \multicolumn{2}{|c|}{1.175} & \multicolumn{2}{|c|}{1.19} & \multicolumn{2}{|c|}{1.21} & \multicolumn{2}{|c|}{1.23} \\
\hline & 0.2173 & 0.001437 & 0.2261 & 0.001386 & 0.2226 & 0.001352 & 0.2246 & 0.001295 & 0.2254 & 0.001259 & 0.2253 & 0.001248 \\
\hline & $4.99 \%$ & $5.56 \%$ & $5.93 \%$ & $7.23 \%$ & $7.98 \%$ & $9.09 \%$ & $12.58 \%$ & $13.15 \%$ & $14.12 \%$ & $15.18 \%$ & $14.16 \%$ & $15.32 \%$ \\
\hline \multirow{2}{*}{540,000} & 0.2151 & 0.001453 & 0.2243 & 0.001401 & 0.2251 & 0.001372 & 0.2275 & 0.001313 & 0.2280 & 0.001277 & 0.2279 & 0.001277 \\
\hline & $3.94 \%$ & $4.51 \%$ & $5.80 \%$ & $6.22 \%$ & $6.95 \%$ & $7.74 \%$ & $11.45 \%$ & $11.95 \%$ & $13.11 \%$ & $13.96 \%$ & $13.13 \%$ & $14.17 \%$ \\
\hline \multirow{2}{*}{740,000} & 0.2154 & 0.001448 & 0.2242 & 0.001406 & 0.2253 & 0.001368 & 0.2277 & 0.001315 & 0.2276 & 0.001274 & 0.2277 & 0.001263 \\
\hline & $4.08 \%$ & $4.84 \%$ & $5.04 \%$ & $5.89 \%$ & $6.86 \%$ & $8.01 \%$ & $11.37 \%$ & $11.81 \%$ & $13.28 \%$ & $14.17 \%$ & $13.24 \%$ & $14.31 \%$ \\
\hline
\end{tabular}

Ref. [9] suggests that for predicting the aerodynamic heat of flow around a 2D cylinder, the grid with the cell Reynolds number that represents the minimum normal grid distance to the wall should be less than 8 . Therefore, keeping the total number of mesh cells unchanged, meshes with $y^{+}=0.3,0.15$ and 0.08 were applied when looking for the suitable cell Reynolds number for the wedge section at this stage. The corresponding $y_{H}$ and the cell Reynolds number were about $\left(2.46 \times 10^{-6}, 16\right),\left(1.23 \times 10^{-6}, 8\right)$ and $\left(6.56 \times 10^{-7}, 4\right)$, respectively. Ref. [13] demonstrates that the aspect ratio of the wall cells near the shock is a major factor that influences the simulation performance, and we changed the aspect ratio of the wall cells near the shock to confirm an appropriate value under the following conditions: (1) The total number of mesh cells is unchanged. (2) The cell Reynolds number is unchanged. (3) The changes of aspect ratio are operated in small regions of the wall near shock.

\subsubsection{Numerical Method}

At the high supersonic stage, the density-based solver employing time-derivative preconditioning was used [29]. Ref. [16] concludes that the numerical results of AUSM+ [30,31] and Roe's FDS flux type are closer to the experiment data; these two types were adopted at the high supersonic stage. The validation parameters of the convergence numerical results were as shown in Table 9.

\subsubsection{Simulation Parameters}

Based on the SST k-omega and Spalart-Allmaras turbulence models, combined with two flux types, we adopted three different cell Reynolds numbers to carry out multiple groups of simulation at $T_{W}=100 \mathrm{~K}$. Figure 12a presents the wall pressure coefficient distributions from the experiment and the simulation adopting the SST k-omega model, where $X$-axis is the ratio between the location of $x$ and $L$, and the $Y$-axis is the wall pressure coefficient. The overall distribution trend of the simulation data matches well with the experiment data and the simulation results are very close to the experiment data at the upper stream of the wedge section, where $x / L$ is between 0 and 1 . At the wedge section of interest, where $x / L$ is greater than 1 , the error ratio distribution of numerical data with the experimental data is illustrated in Figure $12 b$. The results based on cell Reynolds number of 
16 and the AUSM+ flux type were the closest to the experimental data and the average error ratio was about $10.73 \%$. Further, another four simulations with different aspect ratios based on a cell Reynolds number of 16 and the AUSM+ flux type were performed. The aspect ratios 400, 200, 100, and 50 were adopted; Figure 13a reveals the distribution diagram of the error ratio of the pressure coefficient. As the aspect ratio decreased, the error ratio decreased. When the aspect ratio was equal to 100 , the optimal simulation results could be obtained, and the mean error, error variance, and mean error ratio were $0.022,5.47 \times 10^{-5}$, and $9.1 \%$, respectively. Subsequently, as the aspect ratio decreased, the error ratio increased.

Table 9. Validation parameters of convergence results at the high supersonic stage.

\begin{tabular}{|c|c|c|}
\hline Validation Parameters & & \\
\hline Solver & $\begin{array}{c}\text { Density-based } \\
\text { Flux: AUSM+/ROE }\end{array}$ & $\begin{array}{c}\text { Density-based } \\
\text { Flux: AUSM+/ROE }\end{array}$ \\
\hline Models & SST k-omega & Spalart-Allmaras \\
\hline Materials & $\begin{array}{c}\text { Density: Ideal-gas } \\
\text { Viscosity: Sutherland law } \\
\mathrm{C}_{\mathrm{p}}(\mathrm{j} / \mathrm{kg}-\mathrm{k}): 1006.43\end{array}$ & $\begin{array}{c}\text { Density: Ideal-gas } \\
\text { Viscosity: Sutherland law } \\
\mathrm{C}_{\mathrm{p}}(\mathrm{j} / \mathrm{kg}-\mathrm{k}): 1006.43\end{array}$ \\
\hline Initial conditions & $\begin{array}{l}\quad \text { Mach number: } 5 \\
\text { Static pressure: } 850.5173 \mathrm{~Pa} \\
\text { Static Temperature: } 79.17 \mathrm{~K}\end{array}$ & $\begin{array}{l}\quad \text { Mach number: } 5 \\
\text { Static pressure: } 850.5173 \mathrm{~Pa} \\
\text { Static Temperature: } 79.17 \mathrm{~K}\end{array}$ \\
\hline Boundary conditions & $\begin{array}{l}\text { INPUT: pressure far field } \\
\text { FARFIELD: pressure far field } \\
\text { OUTPUT: pressure outlet } \\
\text { WALL: no-slip, isothermal, } \\
100 \mathrm{~K} / 290 \mathrm{~K}\end{array}$ & $\begin{array}{l}\text { INPUT: pressure far field } \\
\text { FARFIELD: pressure far field } \\
\text { OUTPUT: pressure outlet } \\
\text { WALL: no-slip, isothermal, } \\
100 \mathrm{~K} / 290 \mathrm{~K}\end{array}$ \\
\hline
\end{tabular}

Figure $13 \mathrm{~b}$ is a comparison of the wall pressure coefficient distribution from the experiment and the simulation adopting the Spalart-Allmaras model at $T_{W}=100 \mathrm{~K}$. The overall distribution trend of the simulation data matched well with the experiment data and the simulation results were very close to the experiment data at the upper stream of the wedge section. The error ratio distribution of the numerical data with the experiment data at the wedge section is displayed in Figure 14a. The results based on a cell Reynolds number of 8 and the AUSM+ flux type were the closest to the experimental data and the average error ratio was about $11.18 \%$. The aspect ratios 400, 200, 100, and 50 were adopted; Figure $14 \mathrm{~b}$ shows the distribution diagram of the error ratio of the pressure coefficient. As the aspect ratio decreased, the error ratio decreased. When the aspect ratio was equal to 200 , the optimal simulation results could be obtained, and the mean error, error variance, and mean error ratio were $0.027,8.95 \times 10^{-5}$, and $10.9 \%$, respectively. Subsequently, as the aspect ratio decreased, the error ratio increased.

To sum up, at $T_{W}=100 \mathrm{~K}$, a grid strategy with a cell Reynolds number of 16 and aspect ratio of 100, combined with a numerical method, adopting the SST k-omega turbulence model, the density-based solver, and the AUSM+ flux type, obtained an optimal simulation.

Similarly, other multiple groups of simulation were performed at $T_{W}=290 \mathrm{~K}$. The overall distribution trend of the simulation data adopting the SST k-omega model matched well with the experiment data, as can be seen in Figure 15a. Figure 15b describes the error ratio distribution of numerical data with the experiment data at the wedge section. The results based on a cell Reynolds number of 16 and an AUSM+ flux type were the closest to the experimental data and the average error ratio was about $8.27 \%$. Further, using the same number of cells, another four simulations with different aspect ratios based on a cell Reynolds number of 16 and an AUSM+ flux type were performed. The aspect ratios 400, 200, 100, and 50 were adopted; Figure 16a demonstrates the distribution diagram of the error ratio of the pressure coefficient. As the aspect ratio decreased, the error ratio decreased. When the aspect ratio was equal to 200, the optimal simulation results could be obtained, and the mean error, error variance and mean error ratio were 0.018, 
$8.16 \times 10^{-5}$, and $7.45 \%$, respectively. Subsequently, as the aspect ratio decreased, the error ratio increased.

Figure $16 \mathrm{~b}$ sums up the wall pressure coefficient distributions from the experiment and the simulation at $T_{W}=290 \mathrm{~K}$ adopting the Spalart-Allmaras model. The overall distribution trend of the simulation data matched well with the experiment data and the simulation results were very close to the experiment data at the upper stream of the wedge section. Figure 17a shows the error ratio distribution of the wall pressure coefficient at the wedge section. The results based on a cell Reynolds number of 16 and an AUSM+ flux type were the closest to the experimental data and the average error ratio was about $11.18 \%$. The aspect ratios 400, 200, 100, and 50 were adopted; Figure $17 \mathrm{~b}$ reveals the distribution diagram of the error ratio of the pressure coefficient. As the aspect ratio decreased, the error ratio decreased. When the aspect ratio was equal to 200, the optimal simulation results could be obtained, and the mean error, error variance. and mean error ratio were 0.027 , $8.95 \times 10^{-5}$, and $10.9 \%$, respectively. Subsequently, as the aspect ratio decreased, the error ratio increased.

Primarily, at $T_{W}=290 \mathrm{~K}$, the optimal results were achieved based on a grid strategy applying a cell Reynolds number of 16 and an aspect ratio of 200, and a numerical method accepting the SST k-omega model, the density-based solver, and the AUSM+ flux type.

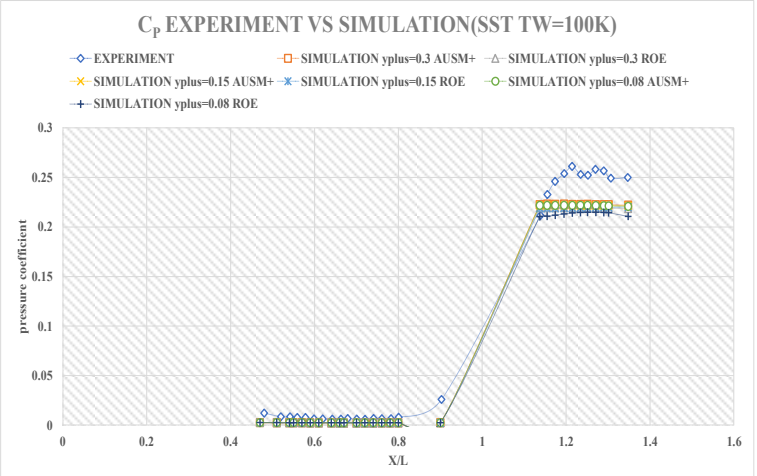

(a)

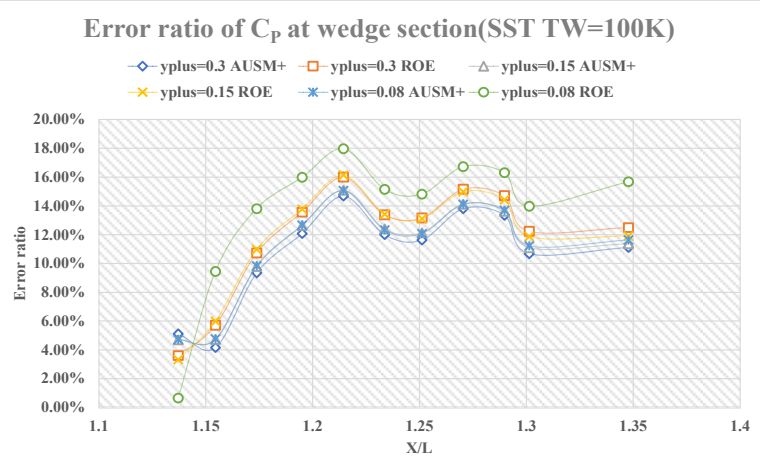

(b)

Figure 12. (a) wall pressure coefficient distribution diagram adopting SST K-omega at $T_{W}=100 \mathrm{~K}$; (b) error ratio of wall pressure coefficient distribution diagram at the wedge section adopting SST K-omega at $T_{W}=100 \mathrm{~K}$.

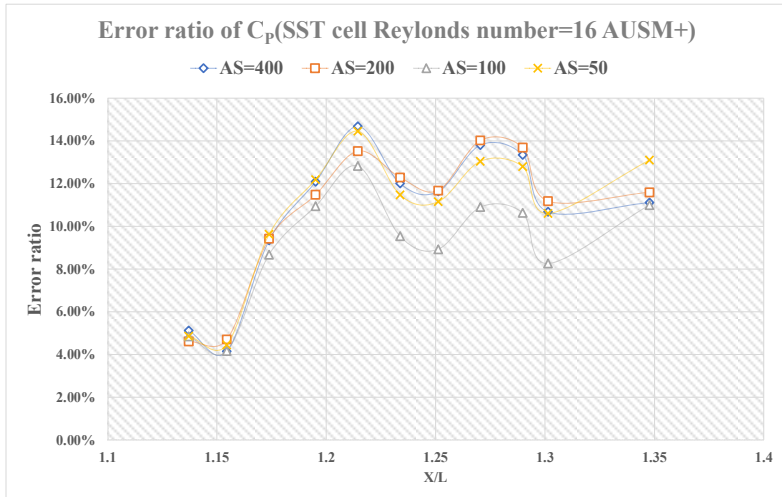

(a)

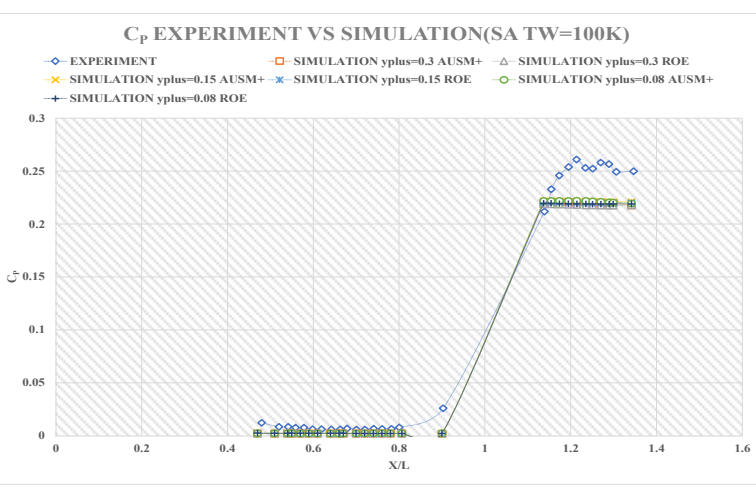

(b)

Figure 13. (a) error ratio of wall pressure coefficient distribution diagram at the wedge section adopting four different aspect ratios; (b) wall pressure coefficient distribution diagram adopting Spalart-Allmaras at $T_{W}=100 \mathrm{~K}$. 


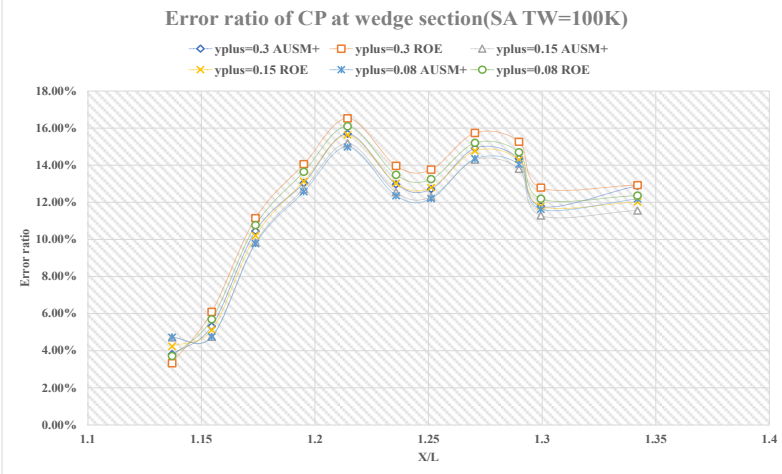

(a)

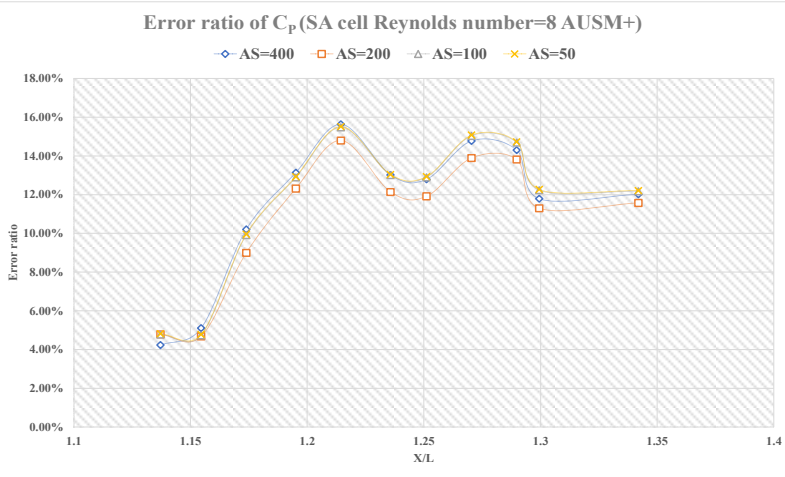

(b)

Figure 14. (a) error ratio of wall pressure coefficient distribution diagram at the wedge section adopting Spalart-Allmaras at $T_{W}=100 \mathrm{~K}$; (b) error ratio of wall pressure coefficient distribution diagram at the wedge section adopting four different aspect ratios.

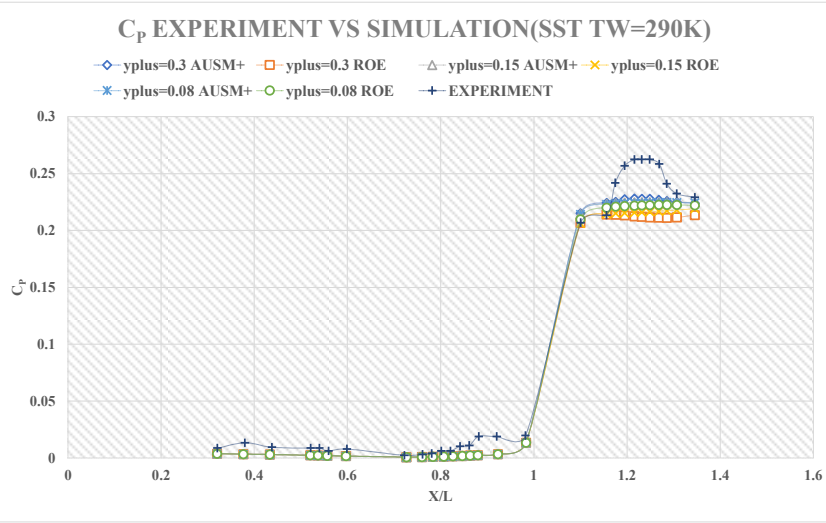

(a)

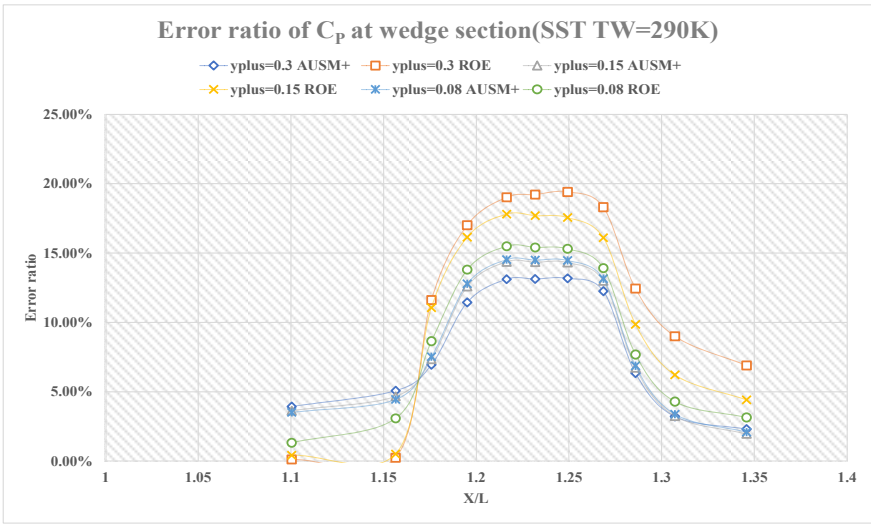

(b)

Figure 15. (a) wall pressure coefficient distribution diagram adopting SST K-omega at $T_{W}=290 \mathrm{~K}$; (b) error ratio of wall pressure coefficient distribution diagram at the wedge section adopting SST K-omega at $T_{W}=290 \mathrm{~K}$.

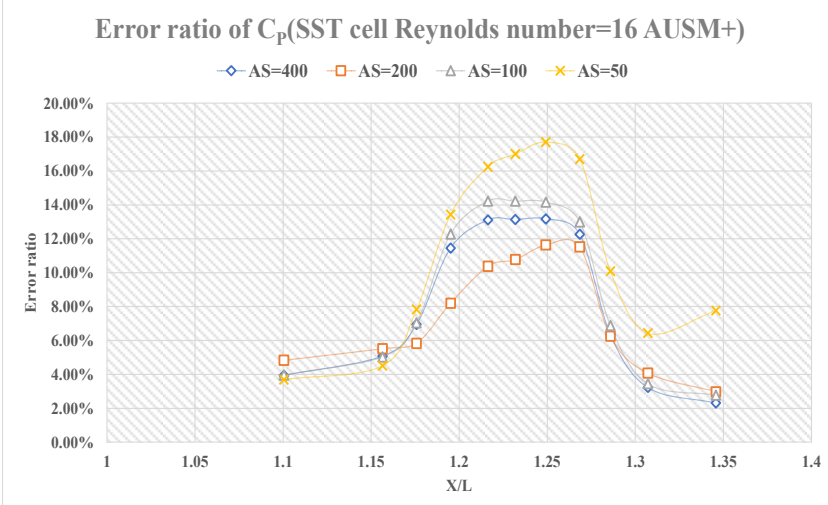

(a)

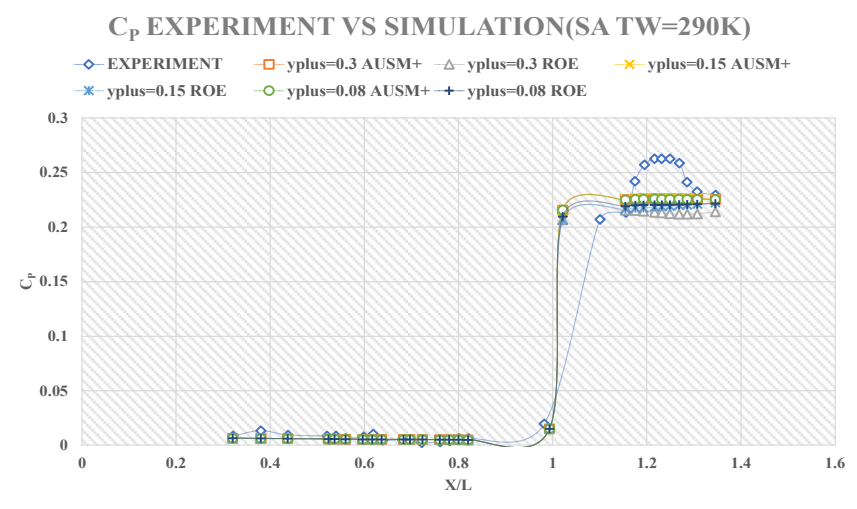

(b)

Figure 16. (a) error ratio of wall pressure coefficient distribution diagram at the wedge section adopting four different aspect ratios; (b) wall pressure coefficient distribution diagram adopting Spalart-Allmaras at $T_{W}=290 \mathrm{~K}$. 


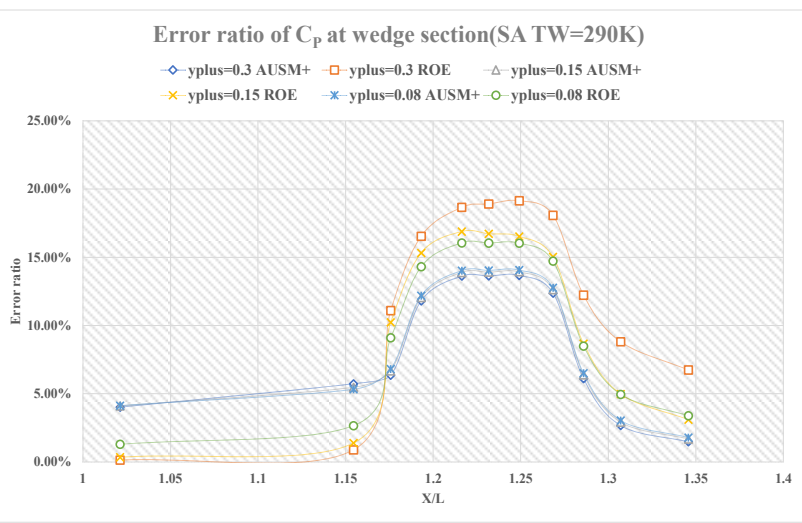

(a)

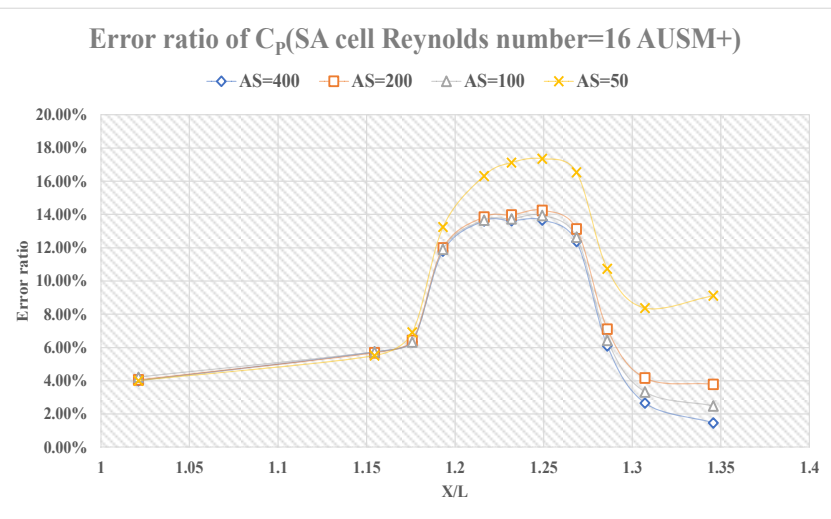

(b)

Figure 17. (a) error ratio of wall pressure coefficient distribution diagram at the wedge section adopting Spalart-Allmaras at $T_{W}$ $=290 \mathrm{~K}$; (b) error ratio of wall pressure coefficient distribution diagram at the wedge section adopting four different aspect ratios.

In conclusion, the performance of the SST k-omega model was better than that of the Spalart-Allmaras model for the wedge section at the high supersonic stage. When $T_{W} / T_{r}$ is less than 0.3 , the mesh with $y^{+}$is 0.3 , the cell Reynolds number is 40 and the aspect ratio is 100, the turbulence model applying Spalart-Allmaras and the density-based solver applying the AUSM+ flux type is preferred. When $T_{W} / T_{r}$ is greater than 0.3 , the mesh with $y^{+}$is 0.3 , the cell Reynolds number is 16 , and the aspect ratio is 200 , the turbulence model applying SST k-omega and the density-based solver applying the AUSM+ flux type is preferred.

\subsection{Hypersonic Stage}

\subsubsection{Grid Strategy}

The experimental data in Ref. [32] were used to validate the simulation parameters at this stage. The Mach number $M$ was 7.05 and the wedge angle $\alpha$ was $20^{\circ}$. The shock angle s was $27.24^{\circ}$, which was calculated by Equation (16). We then established and divided the external flow field model for the simulation, as shown in Figure 18. Line $\mathrm{d}$ is the flat plate and line $g$ is the wedge section. The bold black dot is the $(0,0)$ point of the coordinate system. The bold black square point is the origin of the wedge section (or the interaction of the plate and the wedge). At the hypersonic stage, the static temperature of the freestream $T$ was $81.2 \mathrm{~K}$, the wall temperature $T_{W}$ was $311 \mathrm{~K}$, and the static pressure of the freestream $p$ was $576 \mathrm{~Pa} . M$ was 7.05 and the velocity of the freestream $U$ was $1274 \mathrm{~m} / \mathrm{s}$. The corresponding unit Reynolds number of the freestream was $5.8 \times 10^{6}$, the characteristic length $c$ was $2 \mathrm{~m}$, the air density s was ideal-gas, the specific heat at constant air pressure was $1006.43 \mathrm{j} / \mathrm{kg}-\mathrm{k}$, and the viscosity adopted three-coefficient Sutherland Law.

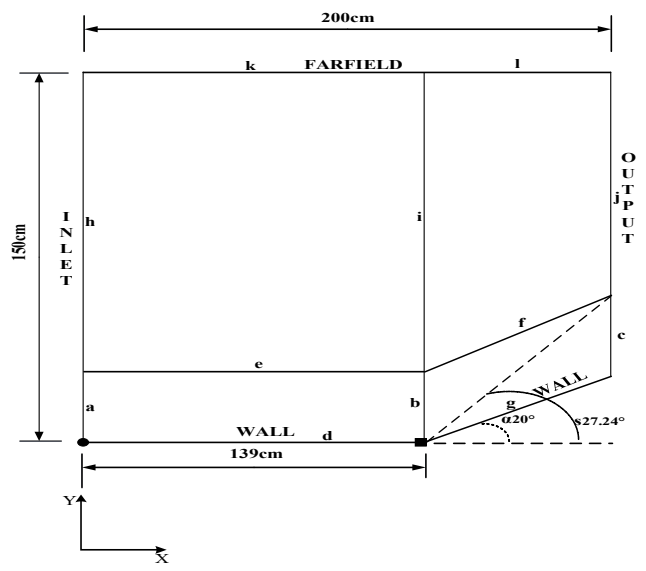

Figure 18. The external flow field simulation model for the high supersonic stage. 
As in the previous stage, the computational region analysis was performed and three sizes were chosen, as shown in Figure 19a [24]. The INLET boundary contains lines a and $\mathrm{h}$, the OUTPUT boundary contains lines $\mathrm{c}$ and $\mathrm{j}$, the FARDIELD boundary contains lines $\mathrm{k}$ and $l$ and the WALL boundary contains lines $d$ and g. Figure 19b shows the close view of the refined mesh near the shock wave region. Taking the Spalart-Allmaras model as an example, the values of $T / T_{I N F}$ and the values of pressure at $S=0.155 \mathrm{~m}$ were as shown in Table 10. $S$ is the distance to the origin point of the wedge along the wedge surface, $y$ is the distance normal to the wedge surface, and $T_{I N F}$ is the freestream's static temperature ahead of interaction, which was $81.2 \mathrm{~K}$. From Table 10, the computational domain with $8 \mathrm{c}$ was chosen for low ratio errors. Three levels of different mesh were tested to be sure of grid independency and from Table 11, the mesh with 650,000 cells was preferred.

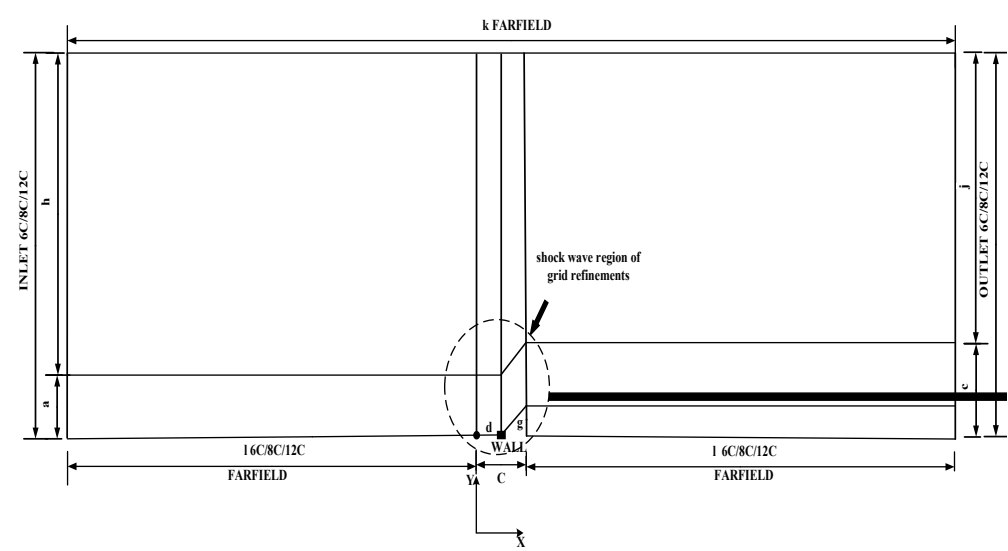

(a)

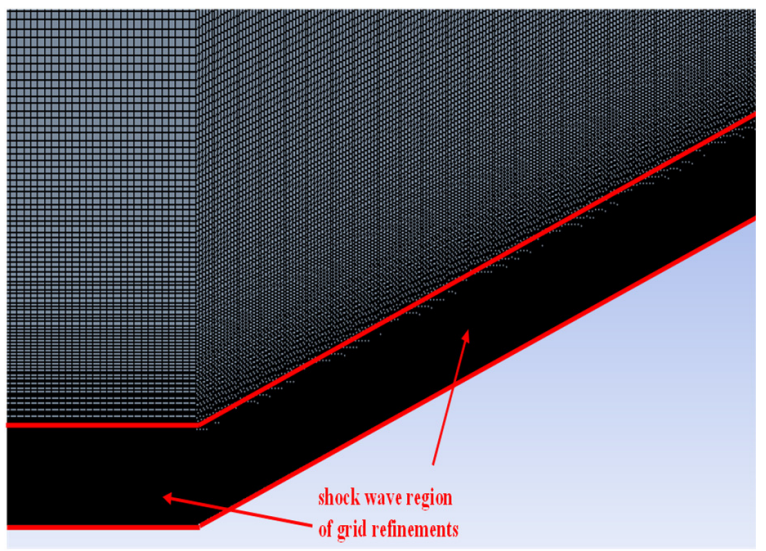

(b)

Figure 19. (a) computational domain; (b) close view of grids in near shock wave region.

Table 10. Computational domain independency study of three levels of sizes with error ratios.

\begin{tabular}{|c|c|c|c|c|c|c|c|c|c|c|c|c|}
\hline \multirow{4}{*}{$\begin{array}{c}\text { Computational } \\
\text { Domains) } \\
6 c\end{array}$} & \multicolumn{12}{|c|}{$\begin{array}{c}y(\mathrm{~cm}) \\
\left(\mathrm{U} / \mathrm{U}_{\mathrm{INF}}, \text { Pressure and Error Ratio) }\right.\end{array}$} \\
\hline & \multicolumn{2}{|c|}{0.2} & \multicolumn{2}{|c|}{0.5} & \multicolumn{2}{|c|}{0.8} & \multicolumn{2}{|c|}{1.1} & \multicolumn{2}{|c|}{1.4} & \multicolumn{2}{|c|}{1.6} \\
\hline & 3.6211 & 6579.27 & 2.9443 & 6561.08 & 2.9117 & 6664.32 & 3.0921 & 6759.12 & 3.0671 & 6879.28 & 3.1098 & 6902.17 \\
\hline & $3.79 \%$ & $7.40 \%$ & $7.82 \%$ & $7.65 \%$ & $3.87 \%$ & $6.20 \%$ & $8.92 \%$ & $4.87 \%$ & $8.03 \%$ & $3.18 \%$ & $7.79 \%$ & $2.85 \%$ \\
\hline \multirow{2}{*}{$8 c$} & 3.5731 & 6648.16 & 2.9733 & 6629.71 & 2.9434 & 6731.84 & 3.0552 & 6849.32 & 3.0363 & 6975.39 & 3.0731 & 6989.37 \\
\hline & $2.41 \%$ & $6.43 \%$ & $6.91 \%$ & $6.69 \%$ & $2.83 \%$ & $5.25 \%$ & $7.62 \%$ & $3.60 \%$ & $6.95 \%$ & $1.82 \%$ & $6.52 \%$ & $1.63 \%$ \\
\hline \multirow{2}{*}{$12 \mathrm{c}$} & 3.5892 & 6627.39 & 2.9628 & 6621.96 & 2.9274 & 6719.34 & 3.0729 & 6823.07 & 3.0541 & 6941.97 & 3.0913 & 6959.97 \\
\hline & $2.87 \%$ & $6.72 \%$ & $7.24 \%$ & $6.80 \%$ & $3.35 \%$ & $5.43 \%$ & $8.24 \%$ & $3.97 \%$ & $7.58 \%$ & $2.29 \%$ & $7.15 \%$ & $2.04 \%$ \\
\hline
\end{tabular}

Table 11. Grid independency study of three levels of different mesh with error ratios.

\begin{tabular}{|c|c|c|c|c|c|c|c|c|c|c|c|c|}
\hline \multirow{4}{*}{$\begin{array}{c}\begin{array}{c}\text { Mesh } \\
\text { (Cells) }\end{array} \\
460,000\end{array}$} & \multicolumn{12}{|c|}{$\begin{array}{c}y(\mathrm{~cm}) \\
\left(\mathrm{U} / \mathrm{U}_{\mathrm{INF}}, \text { Pressure and Error Ratio) }\right.\end{array}$} \\
\hline & \multicolumn{2}{|c|}{0.2} & \multicolumn{2}{|c|}{0.5} & \multicolumn{2}{|c|}{0.8} & \multicolumn{2}{|c|}{1.1} & \multicolumn{2}{|c|}{1.4} & \multicolumn{2}{|c|}{1.6} \\
\hline & 3.5731 & 6648.16 & 2.9733 & 6629.71 & 2.9434 & 6731.84 & 3.0552 & 6849.32 & 3.0363 & 6975.39 & 3.0731 & 6989.37 \\
\hline & $2.41 \%$ & $6.43 \%$ & $6.91 \%$ & $6.69 \%$ & $2.83 \%$ & $5.25 \%$ & $7.62 \%$ & $3.60 \%$ & $6.95 \%$ & $1.82 \%$ & $6.52 \%$ & $1.63 \%$ \\
\hline \multirow{2}{*}{650,000} & 3.5324 & 6774.72 & 3.0128 & 6755.06 & 2.9840 & 6825.73 & 3.0084 & 6960.94 & 2.9874 & 7066.28 & 3.0342 & 7078.34 \\
\hline & $1.24 \%$ & $4.65 \%$ & $5.67 \%$ & $4.92 \%$ & $1.49 \%$ & $3.93 \%$ & $5.97 \%$ & $2.03 \%$ & $5.23 \%$ & $0.54 \%$ & $5.17 \%$ & $0.37 \%$ \\
\hline \multirow{2}{*}{840,000} & 3.5351 & 6772.48 & 3.0131 & 6753.94 & 2.9843 & 6826.77 & 3.0112 & 6958.31 & 2.9946 & 7069.12 & 3.0297 & 7080.42 \\
\hline & $1.32 \%$ & $4.68 \%$ & $5.66 \%$ & $4.94 \%$ & $1.48 \%$ & $3.92 \%$ & $6.07 \%$ & $2.06 \%$ & $5.48 \%$ & $0.50 \%$ & $5.02 \%$ & $0.35 \%$ \\
\hline
\end{tabular}

As in the high supersonic stage, keeping the total number of mesh cells unchanged, meshes with $y^{+}=0.7,0.35$, and 0.18 were applied to looking for the suitable cell Reynolds number for the wedge section at this stage, according to Ref. [14]. The corresponding $y_{H}$ and 
the cell Reynolds number were about $\left(6.8 \times 10^{-6}, 40\right),\left(3.4 \times 10^{-6}, 20\right)$, and $\left(1.75 \times 10^{-6}, 10\right)$ respectively. Next, based on the appropriate cell Reynolds number, four different aspect ratios were adopted to find the proper aspect ratio for the wedge section under conditions in which the total mesh number and the cell Reynolds number were unchanged.

\subsubsection{Numerical Method}

As in the high supersonic stage, the density-based solver employing time-derivative preconditioning was used. Roe's FDS and AUSM+ flux types were applied. The validation parameters of the convergence numerical results are shown in Table 12.

Table 12. Validation parameters of convergence results at the hypersonic stage.

\begin{tabular}{|c|c|c|}
\hline Validation Parameters & SST k-Omega & Spalart-Allmaras \\
\hline Solver & $\begin{array}{c}\text { Density-based } \\
\text { Flux: AUSM+/ROE }\end{array}$ & $\begin{array}{c}\text { Density-based } \\
\text { Flux: AUSM+/ROE }\end{array}$ \\
\hline Materials & $\begin{array}{c}\text { Density: Ideal-gas } \\
\text { Viscosity: Sutherland law } \\
\mathrm{C}_{\mathrm{p}}(\mathrm{j} / \mathrm{kg}-\mathrm{k}): 1006.43\end{array}$ & $\begin{array}{c}\text { Density: Ideal-gas } \\
\text { Viscosity: Sutherland law } \\
C_{\mathrm{p}}(\mathrm{j} / \mathrm{kg}-\mathrm{k}): 1006.43\end{array}$ \\
\hline Initial conditions & $\begin{array}{c}\text { Mach number: } 7.05 \\
\text { Static pressure: } 576 \mathrm{~Pa} \\
\text { Static Temperature: } 81.2 \mathrm{~K}\end{array}$ & $\begin{array}{c}\text { Mach number: } 7.05 \\
\text { Static pressure: } 576 \mathrm{~Pa} \\
\text { Static Temperature: } 81.2 \mathrm{~K}\end{array}$ \\
\hline Boundary conditions & $\begin{array}{c}\text { INPUT: pressure far field } \\
\text { FARFIELD: pressure far field } \\
\text { OUTPUT: pressure outlet } \\
\text { WALL: no slip, isothermal wall, } 311 \mathrm{~K}\end{array}$ & $\begin{array}{c}\text { INPUT: pressure far field } \\
\text { FARFIELD: pressure far field } \\
\text { OUTPUT: pressure outlet } \\
\text { WALL: no slip, isothermal wall, } 311 \mathrm{~K}\end{array}$ \\
\hline
\end{tabular}

\subsubsection{Simulation Parameters}

Based on the SST k-omega and Spalart-Allmaras turbulence models, combined with two flux types, we adopted three different cell Reynolds numbers to carry out multiple groups of simulations, and the simulation tests showed that a cell Reynolds number of 40 was the appropriate value for the wedge section. $S$ is the distance to the original point of the wedge along the wedge surface and $Y$ is the normal distance to the wedge surface. $T_{I N F}$ is the freestream's static temperature ahead of interaction, which was $81.2 \mathrm{~K}$. $U_{I N F}$ is the freestream's velocity ahead of interaction, which was $1274 \mathrm{~m} / \mathrm{s} . T$ and $U$ are the local freestream temperature and velocity, respectively. Figure 20 shows distribution diagrams of $T / T_{I N F}$ and $U / U_{I N F}$ versus $Y$ from the experiment and the simulation, respectively, at $S=0.055 \mathrm{~m}$. The identical distribution diagrams at $S=0.105 \mathrm{~m}$ and $S=0.155 \mathrm{~m}$ are depicted in Figures 21 and 22, respectively. The overall distribution trend of the simulation data matched well with the experiment data. The results based on the Spalart-Allmaras turbulence model, the cell Reynolds number of 40 and AUSM+ flux type were the closest to the experimental data, and the average error ratio of $T / T_{I N F}$ and $U / U_{I N F}$ were about $(7.41 \%$ $3.1 \%),(5.46 \% 2.14 \%)$, and $(6.32 \% 2.22 \%)$, respectively. Further, another four simulations with different aspect ratios based on Spalart-Allmaras, a cell Reynolds number of 40 and an AUSM+ flux type were performed. The aspect ratios 80, 40, 10, and 2 were adopted, and Figures 23-25 represent the distribution diagrams of the error ratios of $T$ and $U$. As depicted in Figure 23, at $S=0.055 \mathrm{~m}$, the mean errors of $T$ and $U$ corresponding to the four aspect ratio conditions were $(7.41 \%, 3.1 \%),(6.04 \%, 2.07 \%),(5.97 \%, 2.05 \%)$, and $(5.43 \%, 1.93 \%)$, and the optimal simulation results were obtained when the aspect ratio was 2. In Figures 24 and 25, we can observe the same consequences. At $S=0.105 \mathrm{~m}$, the mean errors of $T$ and $U$ corresponding to the four aspect ratio conditions were $(5.46 \%, 2.18 \%),(4.96 \%, 2.17 \%),(4.96 \%$, $2.17 \%)$, and $(4.89 \%, 2.16 \%)$. At $S=0.155 \mathrm{~m}$, the mean errors of $T$ and $U$ corresponding to the four aspect ratio conditions were $(6.32 \%, 2.59 \%),(6.04 \%, 2.56 \%),(6.03 \%, 2.56 \%)$, and $(6.01 \%, 2.54 \%)$. When the aspect ratio decreased from 80 to 40 , the error ratios of $\mathrm{T}$ and $\mathrm{U}$ were reduced to a certain extent. However, with the further reduction of the aspect ratio, the optimization effect of the numerical calculation decreased. At $S$ equals $0.055 \mathrm{~m}$, the maximum changes of error ratio of $T$ and $U$ were $0.54 \%$ and $0.12 \%$, respectively; at $S$ equals 
$0.105 \mathrm{~m}$ and $0.155 \mathrm{~m}$, the error ratio of $T$ and $U$ was almost unchanged. To sum up, the aspect ratio for the wedge section at the hypersonic stage was no larger than 40 .

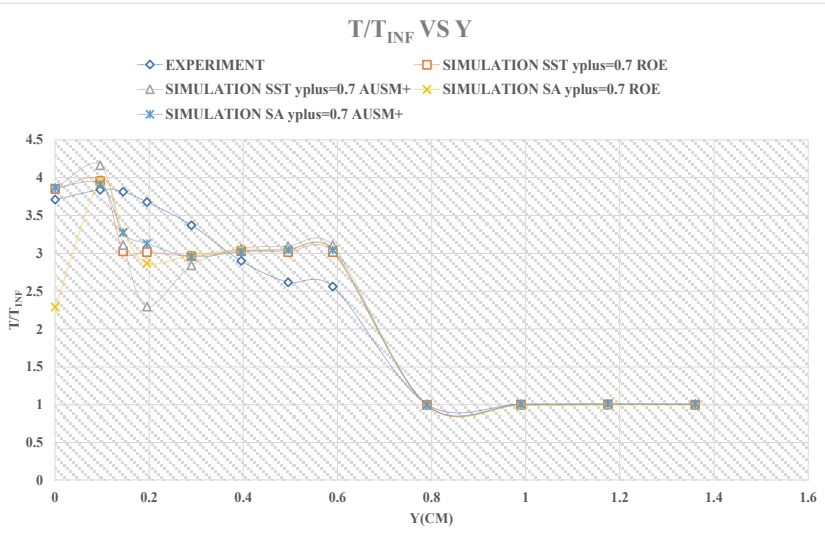

(a)

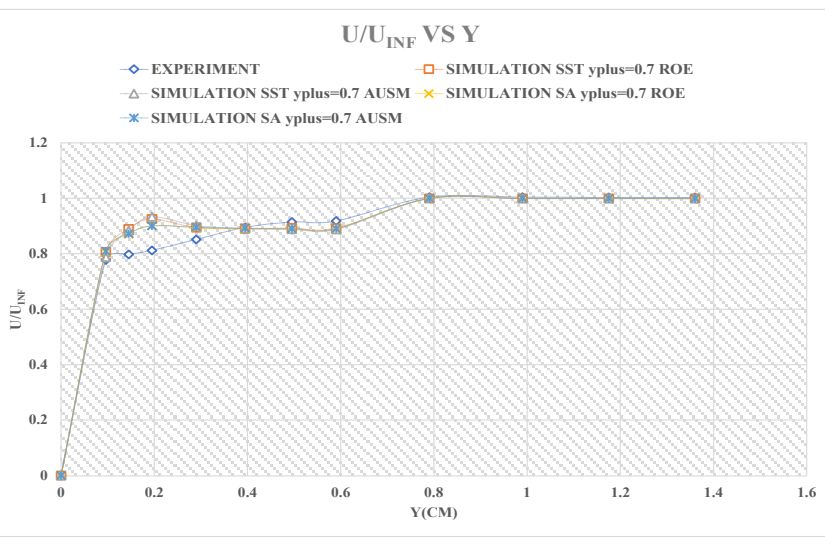

(b)

Figure 20. (a) ratio distribution diagrams between $\mathrm{T}$ and TINF at $\mathrm{S}=0.055 \mathrm{~m}$; (b) ratio distribution diagrams between $\mathrm{U}$ and UINF at $\mathrm{S}=0.055 \mathrm{~m}$.

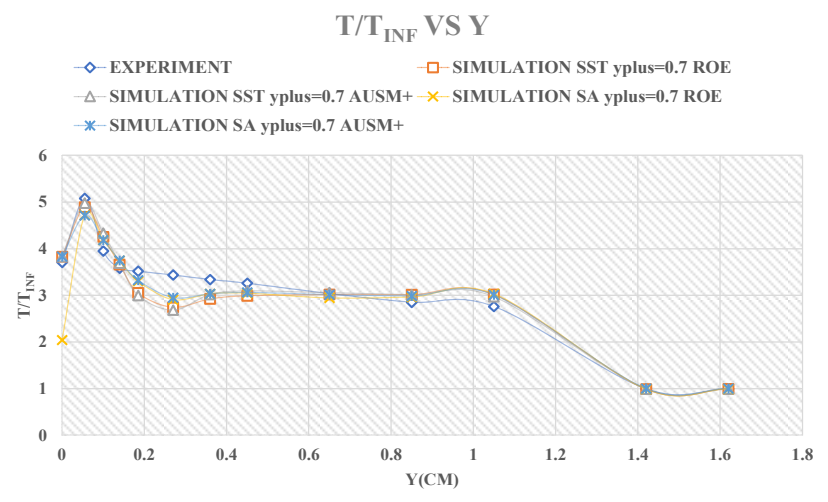

(a)

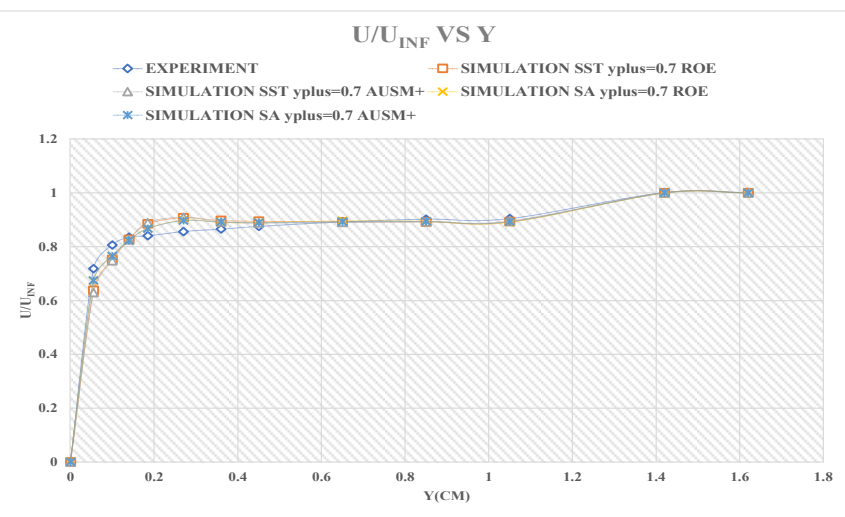

(b)

Figure 21. (a) ratio distribution diagrams between $\mathrm{T}$ and TINF at $\mathrm{S}=0.105 \mathrm{~m}$; (b) ratio distribution diagrams between $\mathrm{U}$ and UINF at $\mathrm{S}=0.105 \mathrm{~m}$.

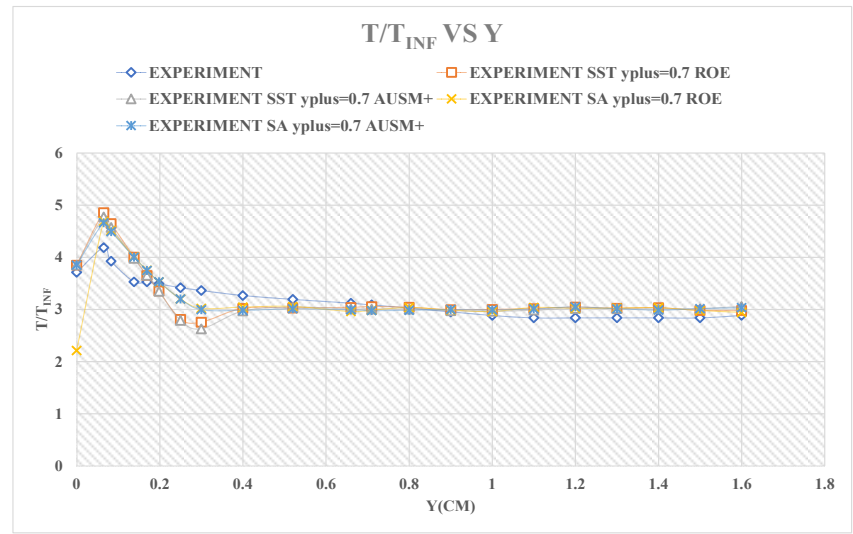

(a)

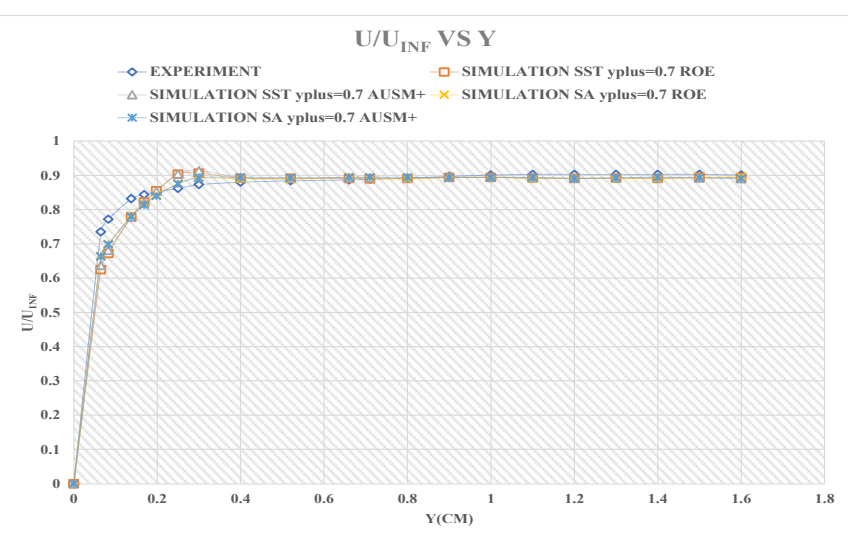

(b)

Figure 22. (a) ratio distribution diagrams between $\mathrm{T}$ and TINF at $\mathrm{S}=0.155 \mathrm{~m}$; (b) ratio distribution diagrams between $\mathrm{U}$ and UINF at $\mathrm{S}=0.155 \mathrm{~m}$. 


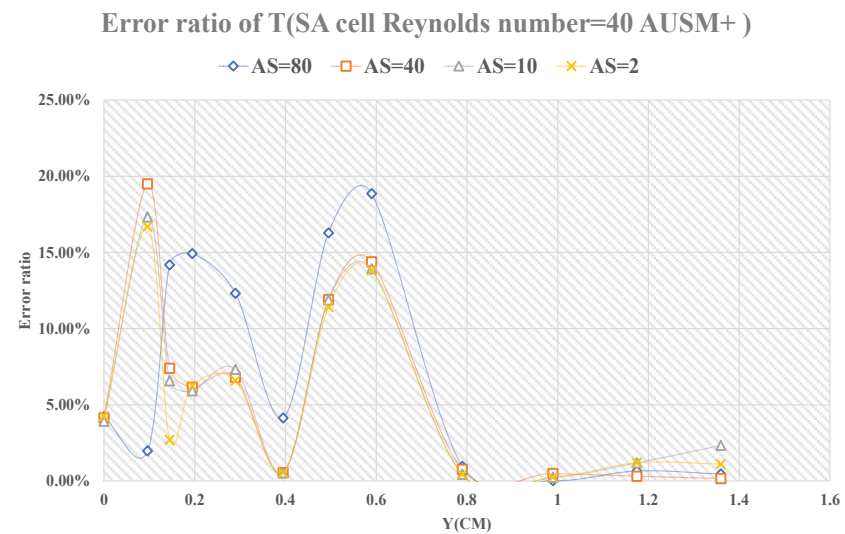

(a)
Error ratio of $\mathrm{U}(\mathrm{SA}$ cell Reynolds number $=40 \mathrm{AUSM}+$ )

$$
\diamond \mathrm{AS}=\mathbf{8 0}-\square-\mathrm{AS}=\mathbf{4 0} \triangle \mathrm{AS}=\mathbf{1 0} \rightarrow \mathrm{AS}=\mathbf{2}
$$

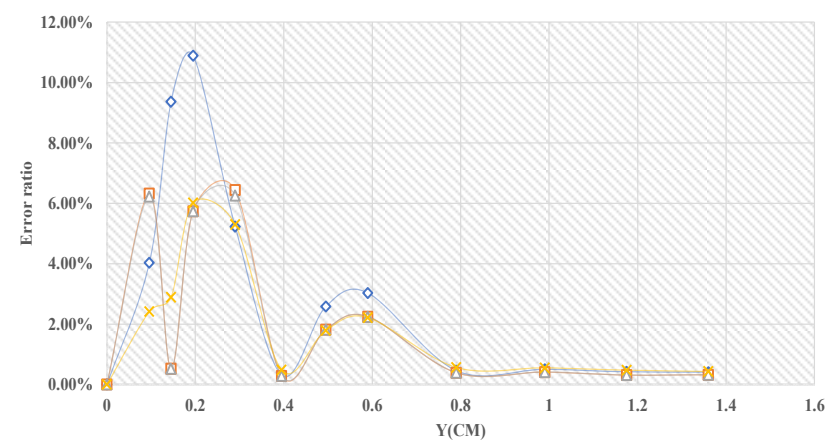

(b)

Figure 23. (a) error ratio distribution diagrams of $\mathrm{T}$ at $\mathrm{S}=0.005 \mathrm{~m}$; (b) error ratio distribution diagrams of $\mathrm{U}$ at $\mathrm{S}=0.005 \mathrm{~m}$.

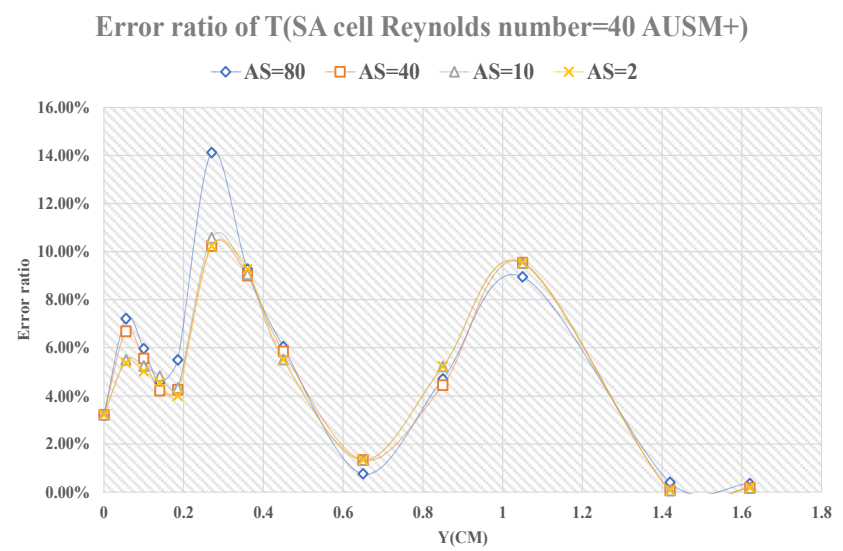

(a)
Error ratio of U(SA cell Reynolds number $=40 \mathrm{AUSM}+$ )

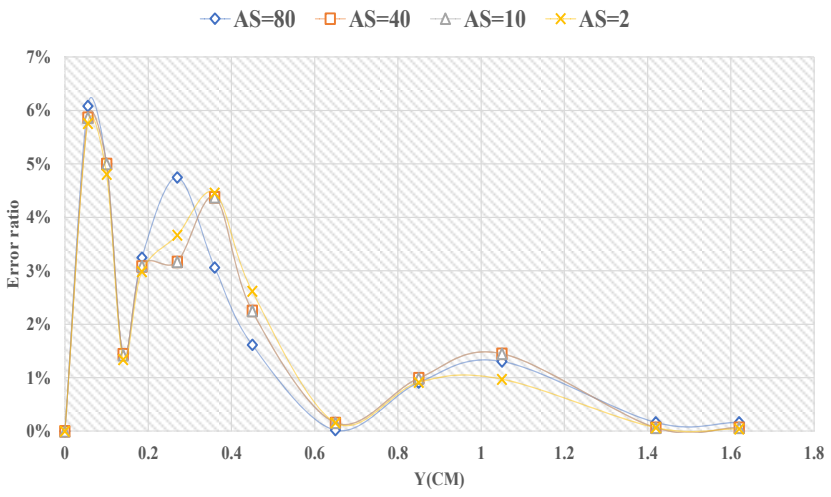

(b)

Figure 24. (a) error ratio distribution diagrams of $\mathrm{T}$ at $\mathrm{S}=0.105 \mathrm{~m}$; (b) error ratio distribution diagrams of $\mathrm{U}$ at $\mathrm{S}=0.105 \mathrm{~m}$.

Error ratio of $\mathrm{T}(\mathrm{SA}$ cell Reynolds number $=40 \mathrm{AUSM}+)$

$$
\sim \mathrm{AS}=\mathbf{8 0}-\square-\mathrm{AS}=\mathbf{4 0}-\triangle \mathrm{AS}=\mathbf{1 0} \times \mathbf{A S}=\mathbf{2}
$$

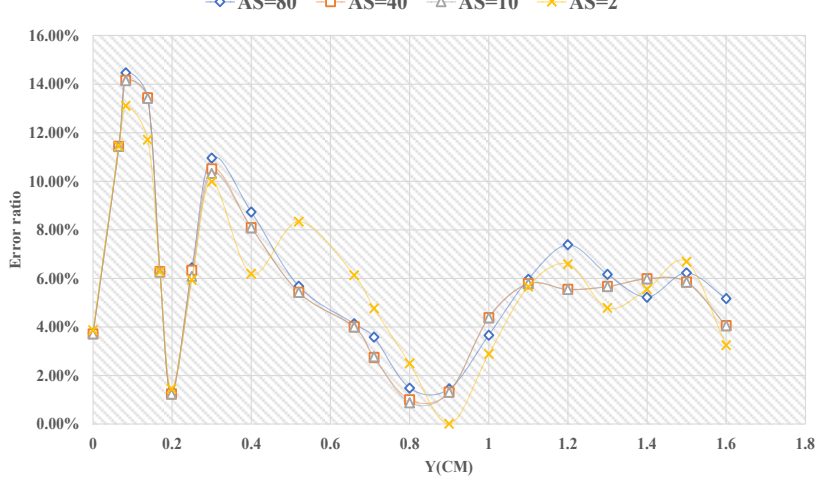

(a)

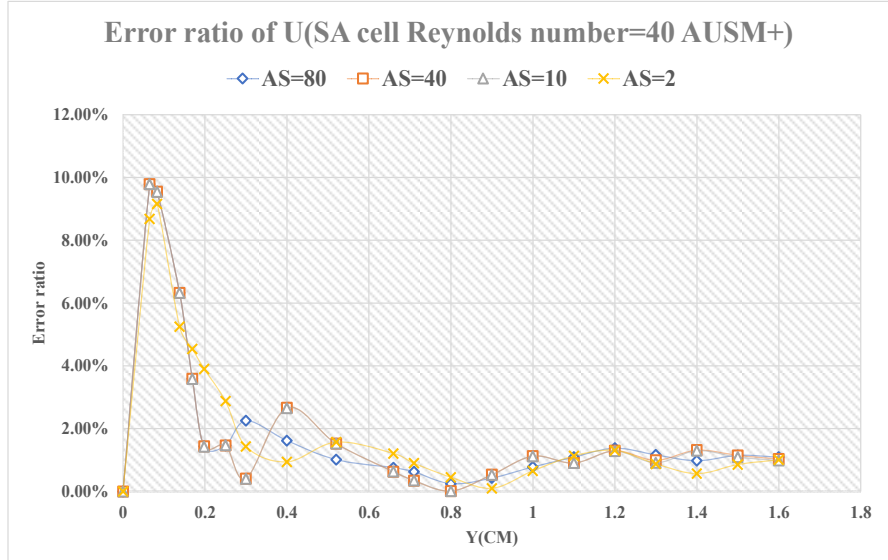

(b)

Figure 25. (a) error ratio distribution diagrams of $\mathrm{T}$ at $\mathrm{S}=0.155 \mathrm{~m}$; (b) error ratio distribution diagrams of $\mathrm{U}$ at $\mathrm{S}=0.155 \mathrm{~m}$.

In conclusion, the performance of the Spalart-Allmaras model was better than that of the SST k-omega model for the wedge section at the hypersonic stage. The mesh with $y^{+}$is 0.7 , the cell Reynolds number is 40 , and the aspect ratio is 40 , the turbulence model 
applying Spalart-Allmaras and the density-based solver applying the AUSM+ flux type is preferred.

\section{Simulation Scheme and Aerothermal Prediction}

Regardless of the influence of fuel and engine performance, it was assumed that the climbing phase would be uniformly accelerated and that the acceleration process would be completed instantly. According to the flight path of the RBCC vehicle in Figure $1 b$, the climbing phase was divided into 34 sub-phases in seconds. Each sub-phase remained at a constant speed and the acceleration of the next sub-phase occurred instantly. Every sub-stage was classified into the corresponding stage described in Section 2, based on Mach number. An effective simulation scheme for predicting the aerodynamic heat of a scramjet-propelled vehicle is shown in Table 13. The external flow field model for the simulation was established based on a wedge-shaped head and the wedge angle $\alpha$ was $20^{\circ}$, as shown in Figure 26.

Table 13. Simulation scheme for aerodynamic heat prediction of RBCC scramjet-propelled vehicle in the flight path.

\begin{tabular}{|c|c|c|}
\hline Phase & Initial Conditions (Altitude, Velocity, Pressure, Temperature, Wall Temperature) & Simulation Parameters \\
\hline Ejection phase & $11 \mathrm{~km} U_{\infty}=0.8 P_{\infty}=22,632 \mathrm{~Pa} T_{\infty}=216.77 \mathrm{~K} T_{W}=216.77 \mathrm{~K}$ & $\begin{array}{c}\text { Transonic stage } \\
\text { Mesh with value of } y^{+} \text {is } 1, \\
\text { turbulence model applying } \\
\text { Spalart-Allmaras and } \\
\text { pressure-based solver adopting } \\
\text { coupled algorithm }\end{array}$ \\
\hline
\end{tabular}

$11.5 \mathrm{~km} U_{\infty}=1.02 P_{\infty}=20,980 \mathrm{~Pa} T_{\infty}=216.65 \mathrm{~K} T_{W}=T_{W}$ result from previous stage $12 \mathrm{~km} U_{\infty}=1.24 P_{\infty}=19,400 \mathrm{~Pa} T_{\infty}=216.65 \mathrm{~K} T_{W}=T_{W}$ result from previous stage

$12.5 \mathrm{~km} U_{\infty}=1.46 P_{\infty}=17,930 \mathrm{~Pa} T_{\infty}=216.65 \mathrm{~K} T_{W}=T_{W}$ result from previous stage $13 \mathrm{~km} U_{\infty}=1.68 P_{\infty}=16,580 \mathrm{~Pa} T_{\infty}=216.65 \mathrm{~K} T_{W}=T_{W}$ result from previous stage Ejection phase $\quad 13.5 \mathrm{~km} U_{\infty}=1.90 P_{\infty}=15,330 \mathrm{~Pa} T_{\infty}=216.65 \mathrm{~K} T_{W}=T_{W}$ result from previous stage $14 \mathrm{~km} U_{\infty}=2.12 P_{\infty}=14,170 \mathrm{~Pa} T_{\infty}=216.65 \mathrm{~K} T_{W}=T_{W}$ result from previous stage $14.5 \mathrm{~km} U_{\infty}=2.34 P_{\infty}=13,100 \mathrm{~Pa} T_{\infty}=216.65 \mathrm{~K} T_{W}=T_{W}$ result from previous stage $15 \mathrm{~km} U_{\infty}=2.56 P_{\infty}=12,110 \mathrm{~Pa} T_{\infty}=216.65 \mathrm{~K} T_{W}=T_{W}$ result from previous stage $15.5 \mathrm{~km} U_{\infty}=2.78 P_{\infty}=11,180 \mathrm{~Pa} T_{\infty}=216.65 \mathrm{~K} T_{W}=T_{W}$ result from previous stage

$16 \mathrm{~km} U_{\infty}=3 P_{\infty}=10,350 \mathrm{~Pa} T_{\infty}=216.65 \mathrm{~K} T_{W}=T_{W}$ result from previous stage $16.5 \mathrm{~km} U_{\infty}=3.15 P_{\infty}=9556 \mathrm{~Pa} T_{\infty}=216.65 \mathrm{~K} T_{W}=T_{W}$ result from previous stage $17 \mathrm{~km} U_{\infty}=3.3 P_{\infty}=8850 \mathrm{~Pa} T_{\infty}=216.65 \mathrm{~K} T_{W}=T_{W}$ result from previous stage $17.5 \mathrm{~km} U_{\infty}=3.45 P_{\infty}=8168 \mathrm{~Pa} T_{\infty}=216.65 \mathrm{~K} T_{W}=T_{W}$ result from previous stage $18 \mathrm{~km} U_{\infty}=3.6 P_{\infty}=7565 \mathrm{~Pa} T_{\infty}=216.65 \mathrm{~K} T_{W}=T_{W}$ result from previous stage $18.5 \mathrm{~km} U_{\infty}=3.75 P_{\infty}=6982 \mathrm{~Pa} T_{\infty}=216.65 \mathrm{~K} T_{W}=T_{W}$ result from previous stage $\begin{array}{lr}\text { Sub combustion } & 19 \mathrm{~km} U_{\infty}=3.9 P_{\infty}=6467 \mathrm{~Pa} T_{\infty}=216.65 \mathrm{~K} T_{W}=T_{W} \text { result from previous stage } \\ \text { stamping phase } & 19.5 \mathrm{~km} U_{\infty}=4.05 P_{\infty}=5968 \mathrm{~Pa}_{\infty}=216.65 \mathrm{~K} T_{W}=T_{W} \text { result from previous stage }\end{array}$ stamping phase $\quad 20 \mathrm{~km} U_{\infty}=4.2 P_{\infty}=5529 \mathrm{~Pa}_{\infty}=216.65 \mathrm{~K} T_{W}=T_{W}$ result from previous stage $20.5 \mathrm{~km} U_{\infty}=4.35 P_{\infty}=5146 \mathrm{~Pa} T_{\infty}=216.65 \mathrm{~K} T_{W}=T_{W}$ result from previous stage $21 \mathrm{~km} U_{\infty}=4.5 P_{\infty}=4729 \mathrm{~Pa} T_{\infty}=216.65 \mathrm{~K} T_{W}=T_{W}$ result from previous stage $21.5 \mathrm{~km} U_{\infty}=4.65 P_{\infty}=4402 \mathrm{~Pa} T_{\infty}=216.65 \mathrm{~K} T_{W}=T_{W}$ result from previous stage $22 \mathrm{~km} U_{\infty}=4.8 P_{\infty}=4048 \mathrm{~Pa} T_{\infty}=218.57 \mathrm{~K} T_{W}=T_{W}$ result from previous stage $22.5 \mathrm{~km} U_{\infty}=4.95 P_{\infty}=3758 \mathrm{~Pa} T_{\infty}=216.65 \mathrm{~K} T_{W}=T_{W}$ result from previous stage

$23 \mathrm{~km} U_{\infty}=5.1 P_{\infty}=3467 \mathrm{~Pa} T_{\infty}=219.57 \mathrm{~K} T_{W}=T_{W}$ result from previous stage $23.5 \mathrm{~km} U_{\infty}=5.25 P_{\infty}=3218 \mathrm{~Pa} T_{\infty}=220.15 \mathrm{~K} T_{W}=T_{W}$ result from previous stage

Sub combustion stamping phase

$24 \mathrm{~km} U_{\infty}=5.4 P_{\infty}=2972 \mathrm{~Pa} T_{\infty}=220.56 \mathrm{~K} T_{W}=T_{W}$ result from previous stage $24.5 \mathrm{~km} U_{\infty}=5.55 P_{\infty}=2753 \mathrm{~Pa} T_{\infty}=221.15 \mathrm{~K} T_{W}=T_{W}$ result from previous stage $25 \mathrm{~km} U_{\infty}=5.7 P_{\infty}=2549 \mathrm{~Pa} T_{\infty}=221.55 \mathrm{~K} T_{W}=T_{W}$ result from previous stage $25.5 \mathrm{~km} U_{\infty}=5.85 P_{\infty}=2361 \mathrm{~Pa} T_{\infty}=222.15 \mathrm{~K} T_{W}=T_{W}$ result from previous stage

$26 \mathrm{~km} U_{\infty}=6 P_{\infty}=2188 \mathrm{~Pa} T_{\infty}=222.54 \mathrm{~K} T_{W}=T_{W}$ result from previous stage $27 \mathrm{~km} U_{\infty}=6.125 P_{\infty}=1880 \mathrm{~Pa} T_{\infty}=223.54 \mathrm{~K} T_{W}=T_{W}$ result from previous stage $28 \mathrm{~km} U_{\infty}=6.25 P_{\infty}=1610 \mathrm{~Pa} T_{\infty}=224.53 \mathrm{~K} T_{W}=T_{W}$ result from previous stage $29 \mathrm{~km} U_{\infty}=6.375 P_{\infty}=1390 \mathrm{~Pa} T_{\infty}=225.52 \mathrm{~K} T_{W}=T_{W}$ result from previous stage

combustion stamping phase
$30 \mathrm{~km} U_{\infty}=6.5 P_{\infty}=1197 \mathrm{~Pa} T_{\infty}=226.51 \mathrm{~K} T_{W}=T_{W}$ result from previous stage
Supersonic stage Mesh with $y^{+}$is 0.8 , turbulence model applying SST k-omega and pressure-based solver adopting coupled algorithm

High supersonic stage Mesh with $y^{+}$is 0.3 , cell Reynolds number of 16 and aspect ratio of 200, turbulence model applying SST

k-omega and density-based solver adopting AUSM+ flux type

Hypersonic stage Mesh with $y^{+}$is 0.7 , cell Reynolds number of 40 and aspect ratio of 40, turbulence model applying Spalart-Allmaras and density-based solver adopting AUSM+ flux type

Hypersonic stage

The same as the above phase

Hypersonic stage

The same as the above phase 


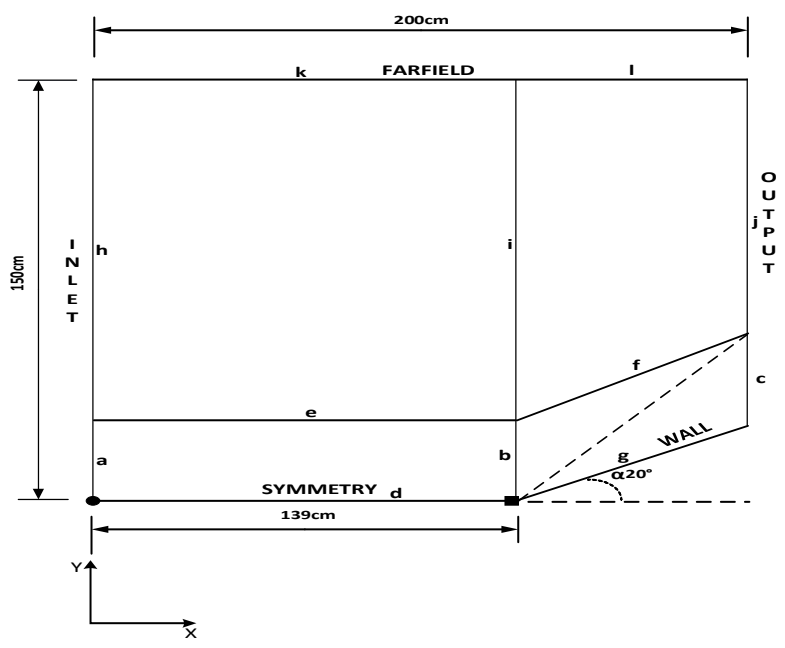

Figure 26. The simulation model for aerothermal prediction of RBCC scramjet-propelled vehicle.

Figure 27 presents the aerodynamic heat of the RBCC scramjet-propelled vehicle in the flight path, as shown in Figure 1b. During the ejection phase, which lasted for about $10 \mathrm{~s}$, the vehicle rose from $11 \mathrm{~km}$ to $16 \mathrm{~km}$ in altitude, the velocity accelerated from $0.8 \mathrm{Ma}$ to $3 \mathrm{Ma}$, and the aerodynamic heat increased from an initial temperature of $216.65 \mathrm{~K}\left(-56.35^{\circ} \mathrm{C}\right)$ to $543 \mathrm{~K}\left(270{ }^{\circ} \mathrm{C}\right)$, with a temperature change of $326.35^{\circ} \mathrm{C}$ and an average temperature change rate of $32.635^{\circ} \mathrm{C} / \mathrm{s}$. During the sub-combustion stamping stage, which lasted for about $20 \mathrm{~s}$, the vehicle rose from $16 \mathrm{~km}$ to $26 \mathrm{~km}$ in altitude, the velocity accelerated from $3 \mathrm{Ma}$ to $6 \mathrm{Ma}$, and the aerodynamic heat increased from a temperature of $543 \mathrm{~K}\left(270^{\circ} \mathrm{C}\right)$ to $1550 \mathrm{~K}\left(1277^{\circ} \mathrm{C}\right)$, with a temperature change of $1007^{\circ} \mathrm{C}$ and an average temperature change rate of 50.35 ${ }^{\circ} \mathrm{C} / \mathrm{s}$. During the super-combustion stamping stage, which lasted for about $4 \mathrm{~s}$, the vehicle rose from $26 \mathrm{~km}$ to $30 \mathrm{~km}$ in altitude, the velocity accelerated from $6 \mathrm{Ma}$ to $6.5 \mathrm{Ma}$, and the aerodynamics heat increased from a temperature of $1550 \mathrm{~K}\left(1277^{\circ} \mathrm{C}\right)$ to $2010 \mathrm{~K}\left(1737^{\circ} \mathrm{C}\right)$, with a temperature change of $460^{\circ} \mathrm{C}$ and an average temperature change rate of $115^{\circ} \mathrm{C} / \mathrm{s}$. During the cruising phase, the vehicle maintained a constant speed and altitude of $6.5 \mathrm{Ma}$ and $30 \mathrm{~km}$, and the aerodynamic heat finally increased to $2130 \mathrm{~K}\left(1857^{\circ} \mathrm{C}\right)$. With the increase of velocity, the average temperature change rate also increased. During a flight time of about $34 \mathrm{~s}$, the aerodynamic heat increased from $216.65 \mathrm{~K}$ to $2130 \mathrm{~K}$, and the temperature change reached about $1913.35^{\circ} \mathrm{C}$, which was consistent with the descriptions in Refs. [33-35], and the maximum average temperature change rate reached $115^{\circ} \mathrm{C} / \mathrm{s}$. The RBCC hypersonic vehicle experienced severe aerodynamic thermal problems during the flight.

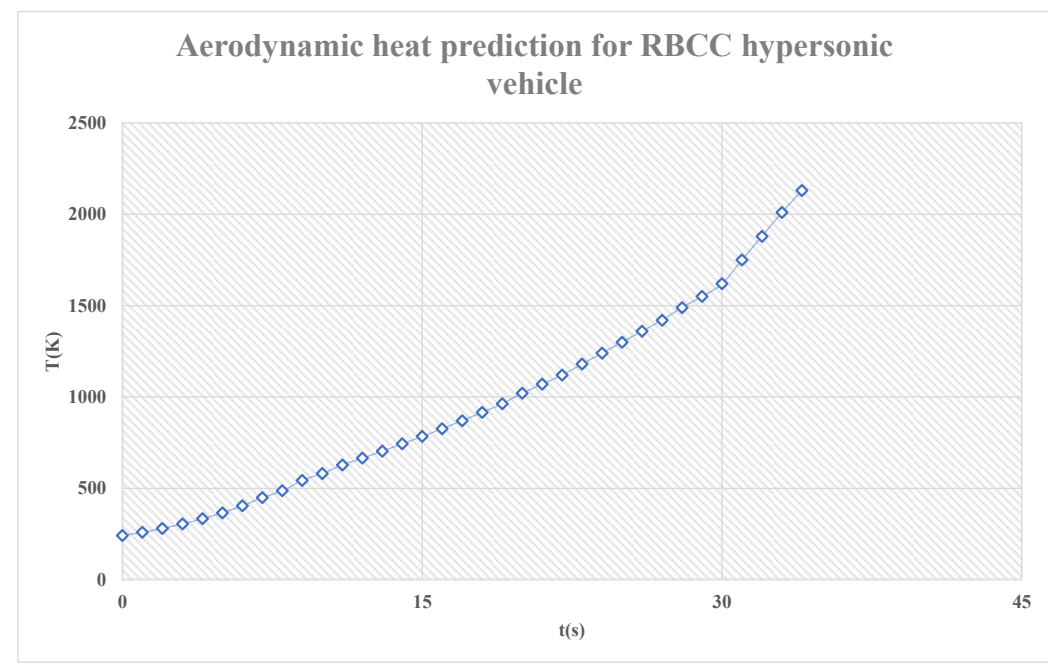

Figure 27. The aerodynamic heat prediction for RBCC scramjet-propelled vehicle in the flight path. 


\section{Conclusions}

In this paper, an effective simulation scheme for predicting the aerodynamic heat of a scramjet-propelled vehicle during flight is proposed. Each phase adopts a different grid strategy and numerical method, which were confirmed by the validation tests described in Section 3. In particular, the flux type dependencies, the cell Reynolds number dependencies, and the aspect ratio dependencies are discussed in Sections 3.3 and 3.4. The aerothermal simulation based on a wedge-shaped head of the RBCC scramjet-propelled vehicle during the climbing phase and cruising phase were performed. Through systematic analysis, several conclusions can be drawn, as follows:

1. For the wedge section in the scramjet-propelled vehicle heating prediction, the suggested value of cell Reynolds number and aspect ratio of wall cells near the shock are different from those for blunt bodies. At the high supersonic stage, the ideal cell Reynolds number should be no larger than 16. At the hypersonic stage, neither the ideal cell Reynolds number, nor the aspect ratio of the wall cells near the shock should be larger than 40 .

2. For the wedge section in the scramjet-propelled vehicle heating prediction, with the same grid strategy, upwind scheme, solver, and so on, the AUSM+ flux type performs better than Roe's FDS flux type. The Spalart-Allmaras turbulence model performs better at the transonic stage and the hypersonic stage, while the SST k-omega performs better at the supersonic stage and the high supersonic stage.

3. Smaller cell Reynolds numbers are not necessarily better. On the one hand, this may cause the quality of the mesh to decrease. On the other hand, as described in Sections 3.3 and 3.4, their improvement of calculation accuracy is limited; they even reduce the accuracy. The value of the aspect ratio is similar to the cell Reynolds number. It is necessary to confirm the appropriate values through CFD analysis based on numerical results and TVR plots.

Author Contributions: Conceptualization, L.Y. and G.Z.; methodology, L.Y. and G.Z.; investigation, L.Y.; formal analysis, L.Y.; resources, L.Y. and G.Z.; validation, L.Y.; visualization, L.Y.; writingoriginal draft preparation, L.Y.; writing-review and editing, G.Z. All authors have read and agreed to the published version of the manuscript.

Funding: This research is financially supported by the National Defense Basic Research Program of China (JCKY2019414D005).

Institutional Review Board Statement: Not applicable.

Informed Consent Statement: Not applicable.

Data Availability Statement: Data is contained within the article.

Conflicts of Interest: The authors declare no conflict of interest.

\section{References}

1. Chen, F.; Liu, H.; Zhang, S. Time-adaptive loosely coupled analysis on fluid-thermal-structural behaviors of hypersonic wing structures under sustained aeroheating. Aerosp. Sci. Technol. 2018, 78, 620-636. [CrossRef]

2. Qu, F.; Kong, W.; Sun, D.; Bai, J. Shock-stable flux scheme for predicting aerodynamic heating load of hypersonic airliners. Sci. China Ser. G: Physics, Mech. Astron. 2019, 62, 984711. [CrossRef]

3. Tao, W.Q. Advances in Computational Heat Transfer, 1st ed.; Science Press: Beijing, China, 2002. (In Chinese)

4. Qu, F.; Sun, D.; Bai, J.; Zuo, G.; Yan, C. Numerical investigation of blunt body's heating load reduction with combination of spike and opposing jet. Int. J. Heat Mass Transf. 2018, 127, 7-15. [CrossRef]

5. Qu, F.; Chen, J.; Sun, D.; Bai, J.; Yan, C. A new all-speed flux scheme for the Euler equations. Comput. Math. Appl. 2019, 77, 1216-1231. [CrossRef]

6. Cook, C.; Balachandar, S.; Chung, J.; Vu-Quoc, L. A generalized Characteristic-Based Split projection method for Navier-Stokes with real fluids. Int. J. Heat Mass Transf. 2018, 124, 1045-1058. [CrossRef]

7. Tsien, H.-S. Superaerodynamics, Mechanics of Rarefied Gases. J. Aeronaut. Sci. 1946, 13, 653-664. [CrossRef]

8. Lee, J.; Rho, O.H. Accuracy of AUSM+ Scheme in Hypersonic Blunt Body Flow Calculations, 8th ed.; AIAA International Space Planes and Hypersonic Systems and Technologies Conference: Norfolk, VA, USA, 1998. 
9. Xiang, Z.; Chao, Y.; Wei, Y.; Haibo, H. Investigation of the grid-dependency in heat transfer simulation for hypersonic vehicle. Tactical Missile Technol. 2016, 3, 21-27. (In Chinese)

10. Qu, F.; Sun, D.; Zuo, G. A study of upwind schemes on the laminar hypersonic heating predictions for the reusable space vehicle. Acta Astronaut. 2018, 147, 412-420. [CrossRef]

11. Di Venuta, I.; Petracci, I.; Angelino, M.; Boghi, A.; Gori, F. Numerical simulation of mass transfer and fluid flow evolution of a rectangular free jet of air. Int. J. Heat Mass Transf. 2018, 117, 235-251. [CrossRef]

12. Kitamura, K.; Shima, E.; Nakamura, Y.; Roe, P.L. Evaluation of Euler Fluxes for Hypersonic Heating Computations. AIAA J. 2010, 48, 763-776. [CrossRef]

13. Qu, F.; Sun, D.; Yan, C. A new flux splitting scheme for the Euler equations II: E-AUSMPWAS for all speeds. Commun. Nonlinear Sci. Numer. Simul. 2018, 57, 58-79. [CrossRef]

14. Qu, F.; Chen, J.; Sun, D.; Bai, J.; Zuo, G. A grid strategy for predicting the space plane's hypersonic aerodynamic heating loads. Aerosp. Sci. Technol. 2019, 86, 659-670. [CrossRef]

15. Smirnov, N.; Penyazkov, O.; Sevrouk, K.; Nikitin, V.; Stamov, L.; Tyurenkova, V. Detonation onset following shock wave focusing. Acta Astronaut. 2017, 135, 114-130. [CrossRef]

16. Li, J.Z.; Yan, C.; Ke, L.; Zhang, S.T. Research on scheme effect of computational fluid dynamics in aerothermal. J. Beijing Univ. Aeronaut. Astronaut. 2003, 11, 1022-1025. (In Chinese)

17. Yang, J.L.; Liu, M. Influence of limiters on numerical simulation of heating distributions for hypersonic bodies. J. Beijing Univ. Aeronaut. Astronaut. 2014, 40, 417-421. (In Chinese)

18. Zheng, X.; Liu, Z.-S.; Yang, Y.; Lei, J.-C.; Li, Z.-X. Research on Climb-cruise Global Trajectory Optimization for RBCC Hypersonic Vehicle. Missiles Space Veh. 2018, 47, 1-8. (In Chinese)

19. Speed of Sound. Available online: https:/ / www.grc.nasa.gov/www/k-12/airplane/sound.html (accessed on 13 May 2021).

20. Spalart, P.; Allmaras, S. A one-equation turbulence model for aerodynamic flows. Rech. Aerosp. 1994, 1, 5-21.

21. Menter, F.R. Two-equation eddy-viscosity turbulence models for engineering applications. AIAA J. 1994, 32, 1598-1605. [CrossRef]

22. Jameson, A.; Schmidt, W.; Turkel, E. Numerical solution of the Euler equations by finite volume methods using Runge Kutta time stepping schemes. In Proceedings of the 14th Fluid and Plasma Dynamics Conference, Palo Alto, CA, USA, 23-25 June 1981; p. 1259.

23. Liepmann, H.W.; Bryson, A.E. Transonic Flow Past Wedge Sections. J. Aeronaut. Sci. 1950, 17, 745-755. [CrossRef]

24. Matin, R.K.; Ghassemi, H.; Arzideh, M.H. Numerical Study of the Effect of Geometrical Changes on the Airfoil Aerodynamic Performance. Int. J. Fluid Mech. Res. 2016, 43, 28-38. [CrossRef]

25. Chorin, A.J. Numerical solution of the Navier-Stokes equations. Math. Comput. 1968, 22, 745. [CrossRef]

26. Barth, T.; Jespersen, D. The design and application of upwind schemes on unstructured meshes. In Proceedings of the 27th Aerospace sclences Meeting, Reno, NV, USA, 9-12 January 1989; p. 366.

27. Stephen, E.; Dunagan, J.L.; John, B.; Miles, B. Interferometric Data for a Shock wave/Boundary-Layer Interaction. In NASA Technical Memorandum 88227; NASA Ames Research Center: Moffett Field, CA, USA, 1986.

28. Delery, J.; Coet, M.C. Experiments on Shock-Wave/Boundary-Layer Interactions Produced by Two-Dimensional Ramps and Three-Dimensional Obstacles. In Hypersonic Flows for Reentry Problems Désidéri; Glowinski, J.A., Périaux, R.J., Eds.; Springer: Berlin/Heidelberg, Germany, 1990.

29. Weiss, J.M.; Smith, W.A. Preconditioning applied to variable and constant density flows. AIAA J. 1995, 33, 2050-2057. [CrossRef]

30. Roe, P.L. Characteristic-Based Schemes for the Euler Equations. Annu. Rev. Fluid Mech. 1986, 18, 337-365. [CrossRef]

31. Chima, R.; Liou, M.-S. Comparison of the AUSM+ and H-CUSP Schemes for Turbomachinery Applications. In NASA Technical Memorandum 212457; NASA Glenn Research Center: Cleveland, OH, USA, 2003.

32. Kussoy, M.I.; Horstman, C.C. Documentation of Two-and Three-Dimensional Hypersonic Shock Wave/Turbulent Boundary Layer Interaction Flows. In NASA Technical Memorandum 101075; NASA Ames Research Center: Moffett Field, CA, USA, 1989.

33. Earl, T. Thermal Structures for Aerospace Applications; AIAA Press: Reston, VA, USA, 1996; p. 5.

34. Wu, D.F.; Shang, L.; Pu, Y.; Wang, H.T.; Gao, Z.T. Experimental research of thermal-insulation performance of lightweight thermal protection materials for hypersonic aircraft in oxidation environment up to $170{ }^{\circ} \mathrm{C}$. Spacecr. Environ. Eng. 2016, 33, 7-12.

35. Wu, D.F.; Lin, L.J.; Wu, W.J.; Sun, C.C. Experimental research on thermal/vibration test of lightweight insulation material for hypersonic vehicle under extreme-high-temperature environment up to $1500{ }^{\circ} \mathrm{C}$. Acta Aeronaut. Astronaut. Sin. 2020, 41, 216-225. 